This article has been scanned by iThenticat No plagiarism detected

Volume 3, Issue 4, August 2021

p. 81-94

\title{
DISTANCE LEARNING, TEACHING AND EVALUATION STRATEGIES IN THE SUBJECT OF “CREATIVE WORKSHOP” FOR EARLY CHILDHOOD http://dx.doi.org/10.47832/2757-5403.4-3.7
}

\section{Maha Mohammad KHALED ${ }^{1}$}

\begin{abstract}
:
The Corona pandemic (covid19) imposed itself on the world in 2020, which called for rapid action to find distance educational solutions, with an experimental approach aimed at the quality and development of learning. It has obligated lecturers in universities of all subjects to learn to use distance learning techniques and to adapt to them, by identifying strategies of distance education, learning and evaluation and linking them to learning outcomes.

These strategies are influencing factors in the success of the e-learning programs (from Zoom Microsoft and others), as alternative programs through which we seek to achieve quality in the distance learning process with the creative workshop subject. The requirements of these modern applications in higher education necessitate focusing on choosing distance learning strategies that lead to active learning and highlight the role and effectiveness of the learner.

Teaching, learning and evaluation strategies vary differ from one program or course to another as a result of their different nature, so this modern method must be implemented on the teacher and the learner professionally in order to compensate for the lack of direct communication.

The research tries to present the most prominent and appropriate strategies of teaching, learning and evaluation in the subject of the creative workshop for early childhood online, up to the mutual evaluation, in addition to detailing the difficulties and obstacles and how to overcome them.
\end{abstract}

Key words: Early Childhood, Creative Workshop, Evaluation Strategies.

\footnotetext{
${ }^{1}$ Prof. Dr. , Lebanese University, Lebanon, drmahakhaled50@hotmail.com, https://orcid.org/0000-0002-0639$\underline{2741}$
}

Copyright (C Published by IJHER Journal, www.ijherjournal.com

Rimar Academy, Fatih, Istanbul, 34093 Turkey

All rights reserved 


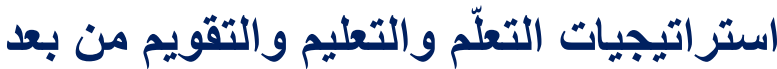 \\ في مادة المشغل الفني طقولة مبكرة}

\section{مها محمد خالا 2}

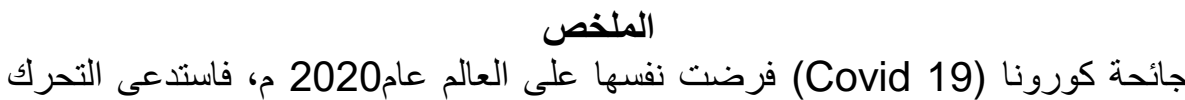

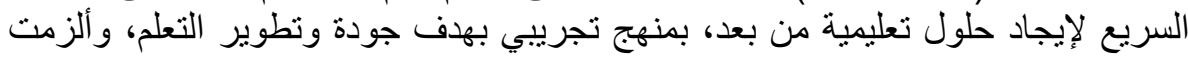

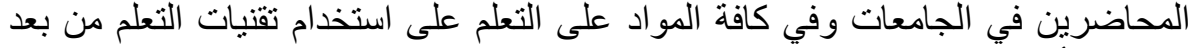

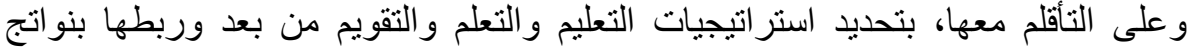
التعلم. تعد هذه الاستراتيجيات عوامل مؤثرة في نجاح البرنامج التعليمية الإلكترونية (من زووم

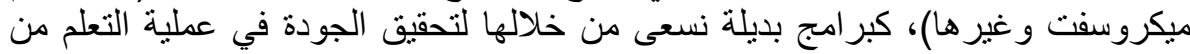

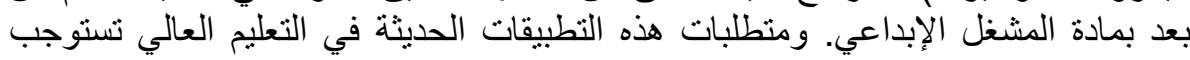

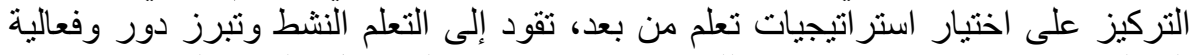

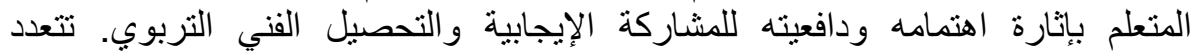

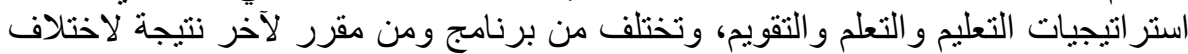

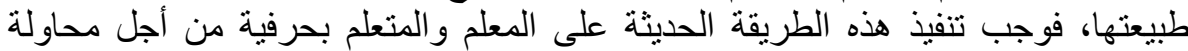

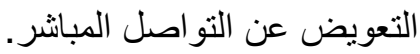

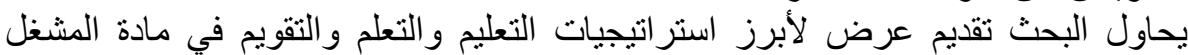

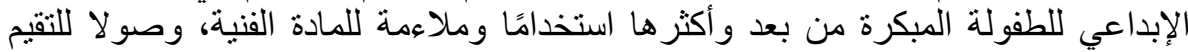

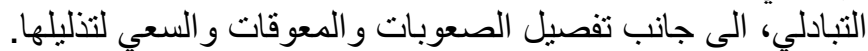
الكلمات المفتاحية: استر اتيجيات التعلّم، المشغل الفني، الطقات الطفولة المبكرة.

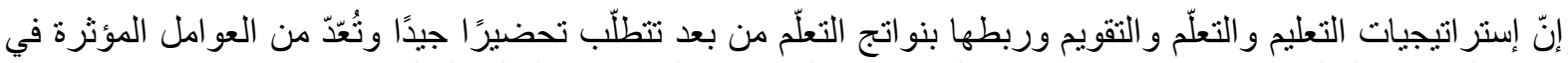

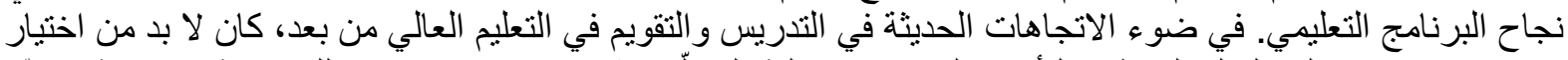

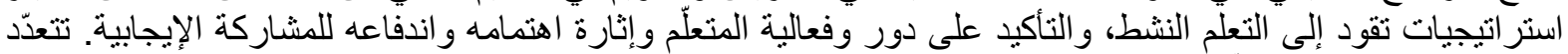

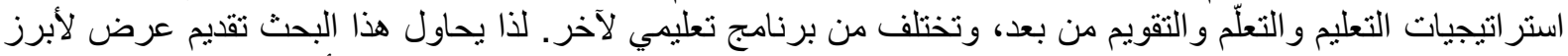

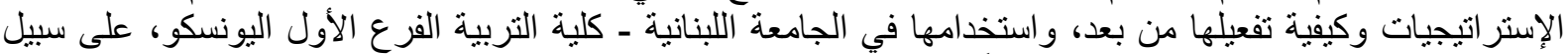

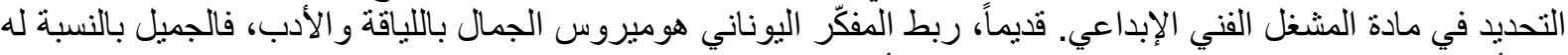

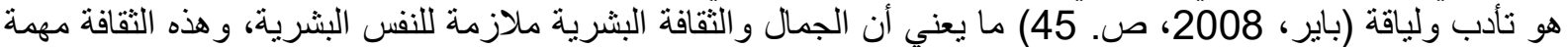

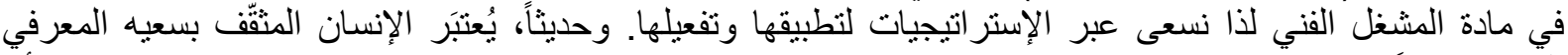
الخاص إنسانًا حرًا في تفتحه وو عياه، هو حر في تحقيق ذاته بكر امة (Lagoutte, 2002, p. 278)، مما يعني أن النان

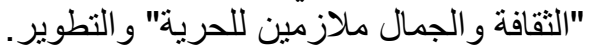

لمحة تاريخية

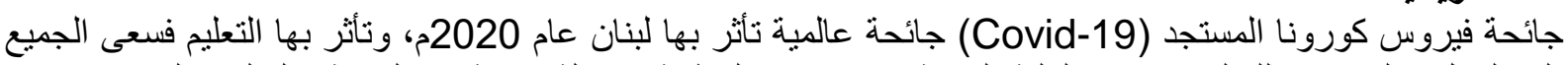

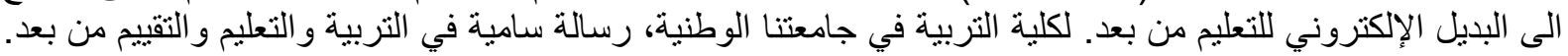

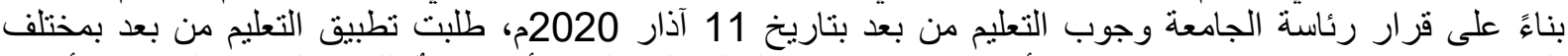

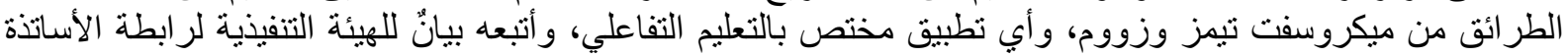

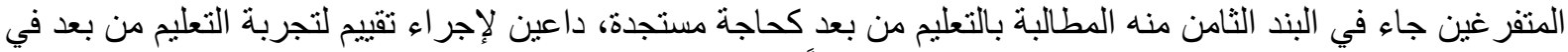

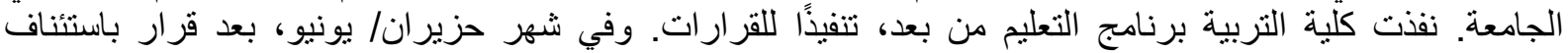

2 أ. د. ، الجامعة اللبنانية، لبنان، drmahakhaled50@hotmail.com 
الدروس في الجامعة اللبنانية في 19حزيران 2020م، بالطرق المناسبة التي ترتأيها إدارات ومجالس الكليات و المعاهد

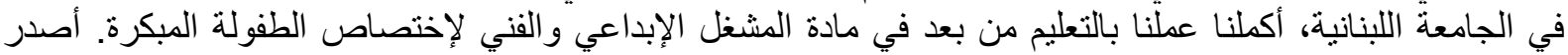

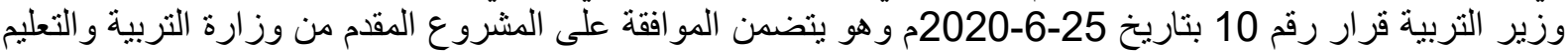

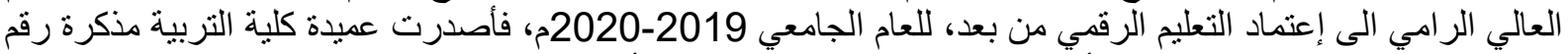

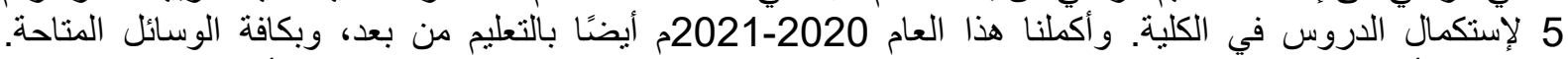

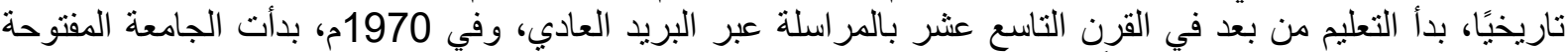

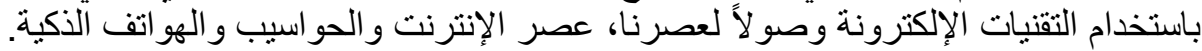
أهمية البحث

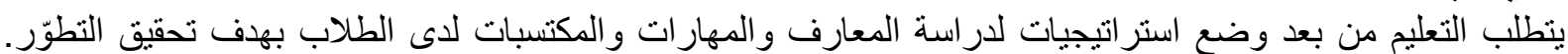

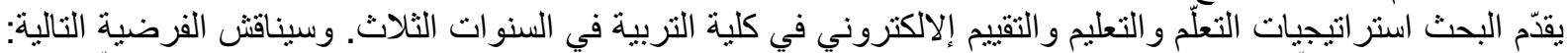

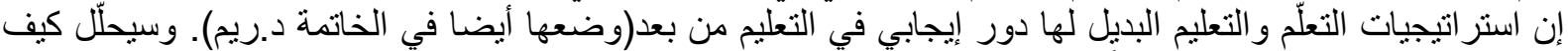

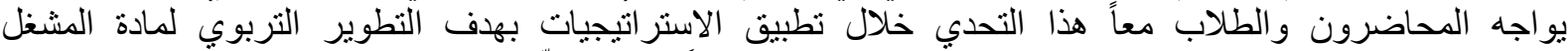

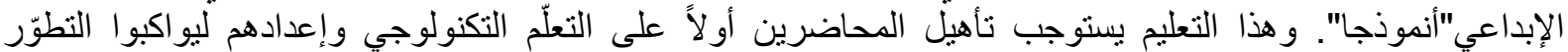

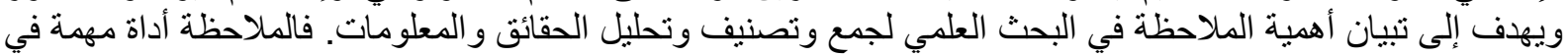

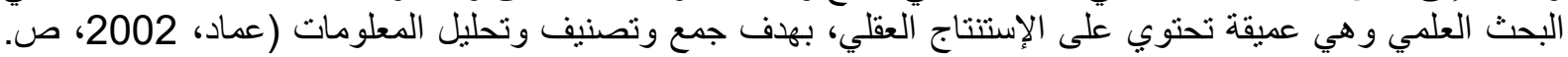

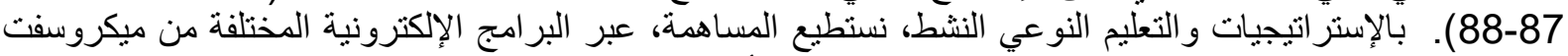

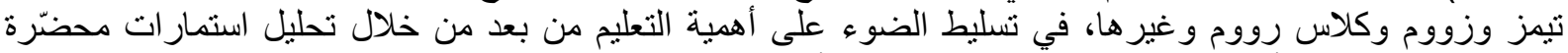

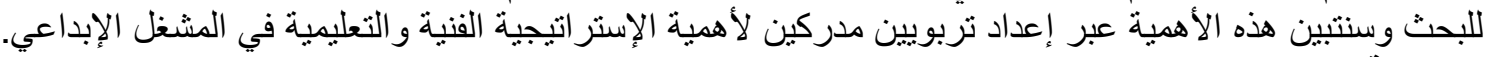
الإثكالية الإنة

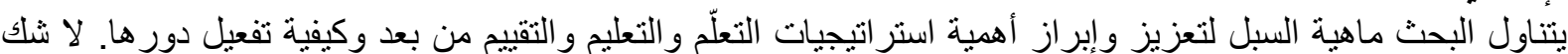

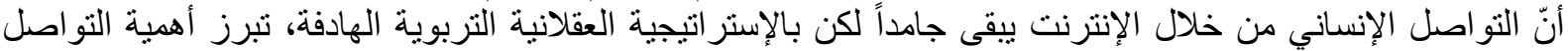
و التفاعل بهدف المسآهمة في زيادة المعارف الإنسانية بنهائية التكامل المعرفي، وبأناناة وصبر.

دراسات سابقة في دراسة صادرة عن اليونسكو تحت عنوان "إطار العمل الإستر اتيجي لليونسكو "للتعليم في حالات الطوارئ في المنطقة الإني

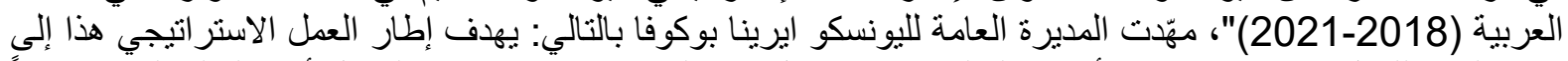

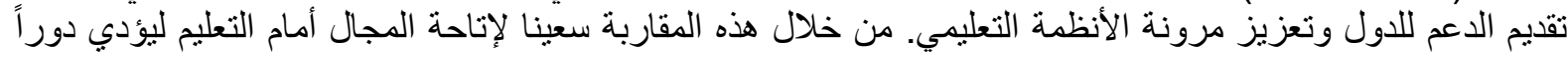

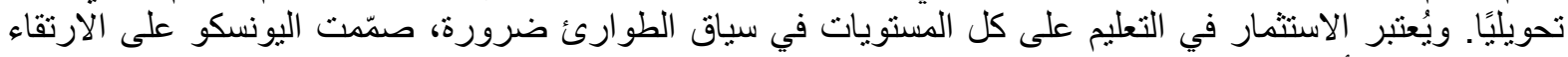

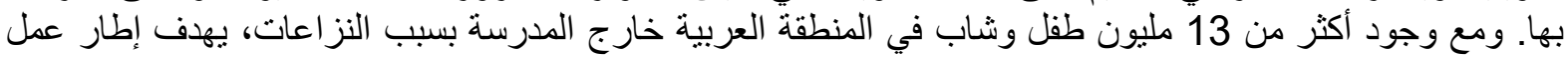

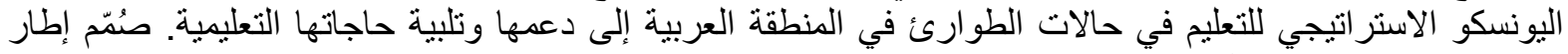

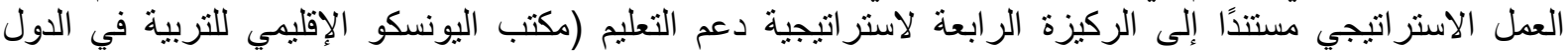

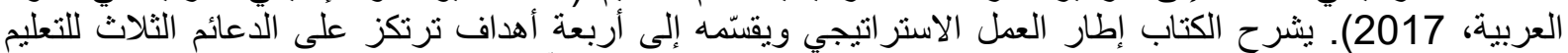

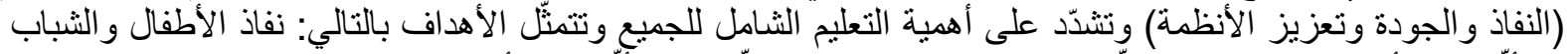

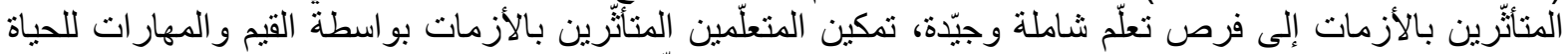

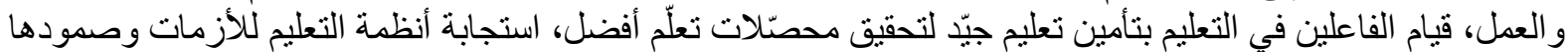

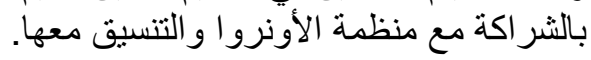




\section{DISTANCE LEARNING, TEACHING AND EVALUATION STRATEGIES \\ IN THE SUBJECT OF "CREATIVE WORKSHOP" FOR EARLY CHILDHOOD}
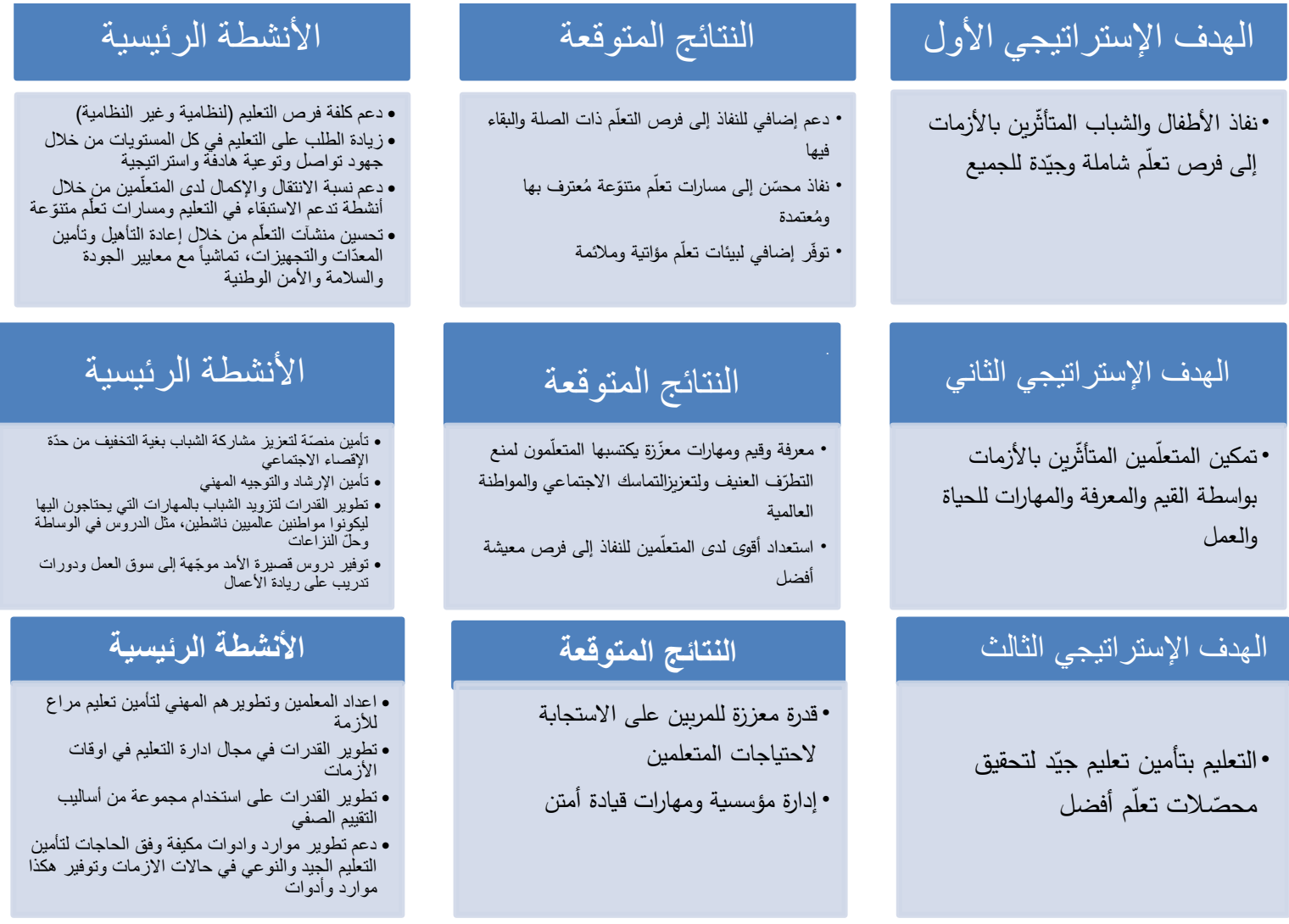

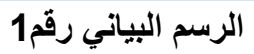

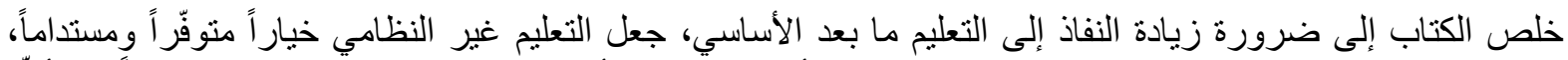

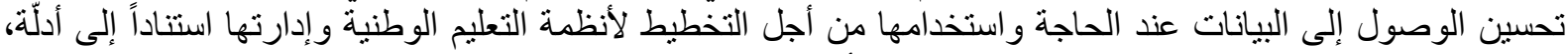

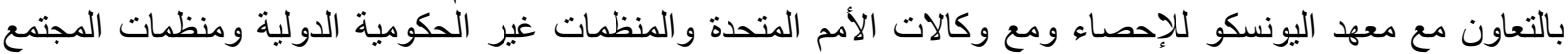

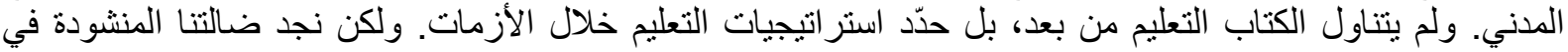

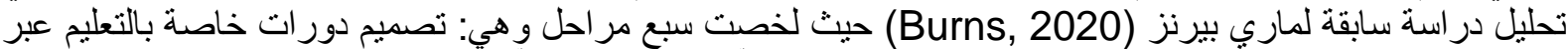

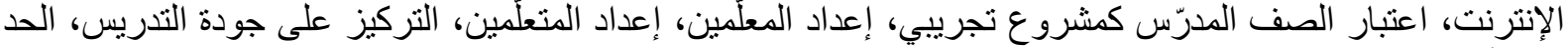

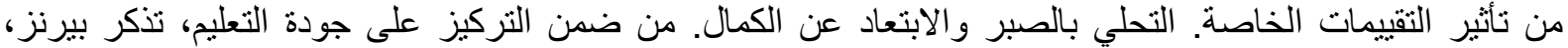

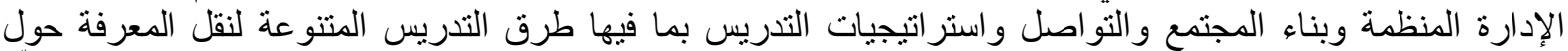

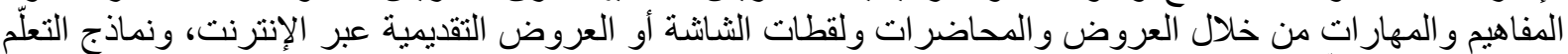

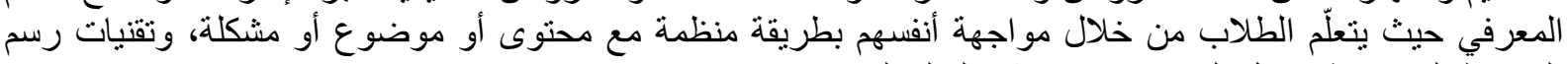
الخرائطً المفاهيمية، وحل المشكلات، ولمن ونماذج التعلم الجماعي.

الفصل الأول

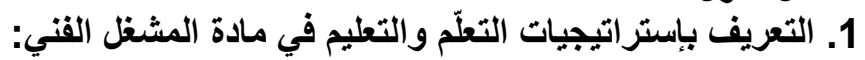

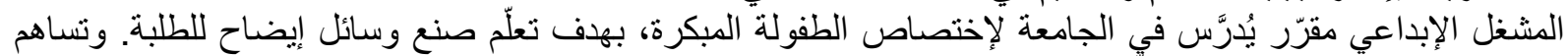

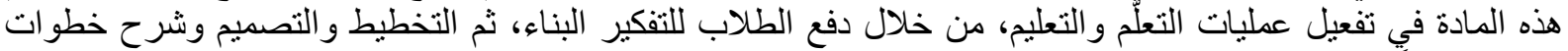

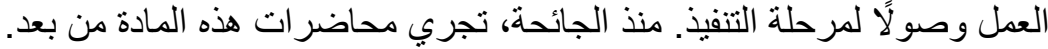
التعليم من بعد (Online Teaching): هو التصميم المنظم للخبرة التي تساعد المتعلّم على إنجاز التغيير المر غوب فيه

في الأداء، بقصد مساعدة المتعلّم على تحقيق أهداف ونو النّ اتج التعلم المستهدفة.

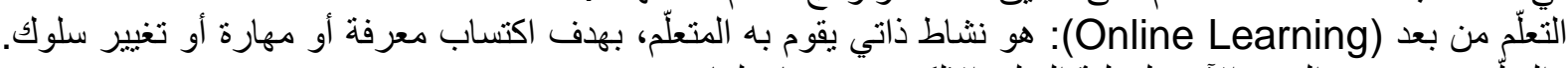
و التعلُم من بعد هو الوجه الآخر لعملية التعليم الالكتروني ونتاج لهان لها. 
الفرق بين التعليم والتعلّم من بعد: التعليم نشاط يقوم به شخص مؤهل لتسهيل اكتساب المتعلّم للمعارف والمهارات

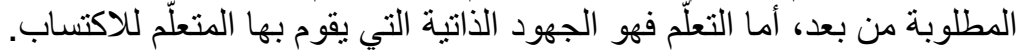

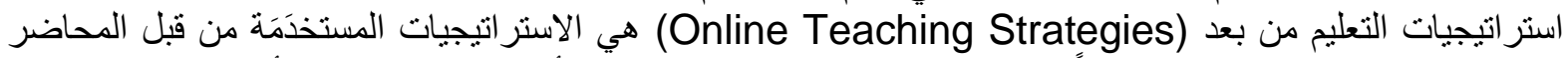

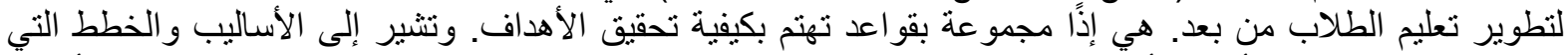

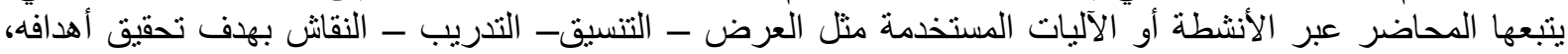

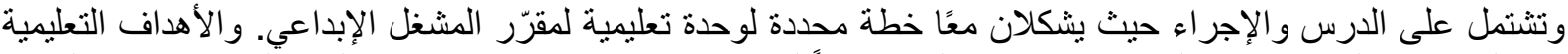

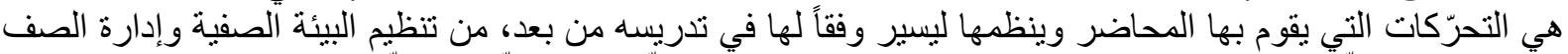

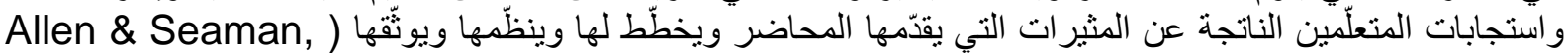
. 2013

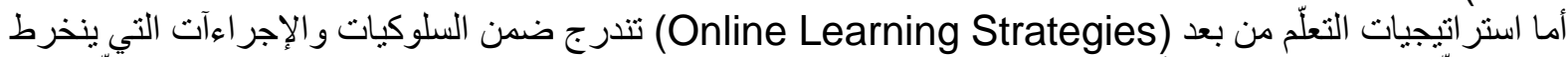

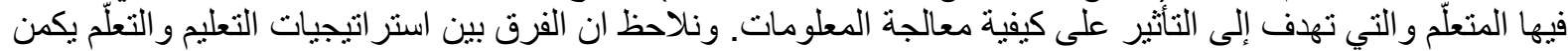

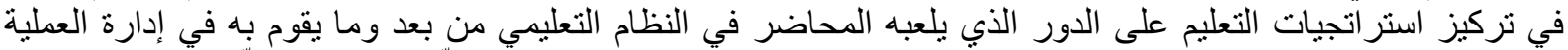

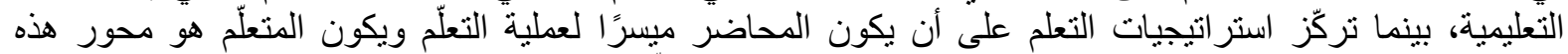

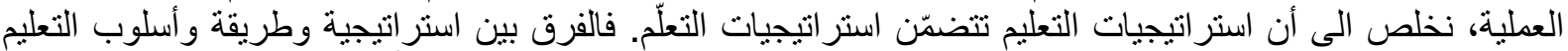

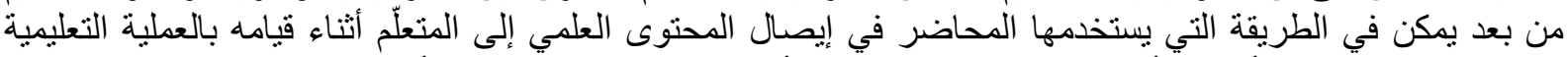

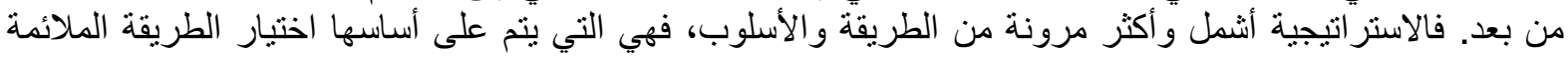

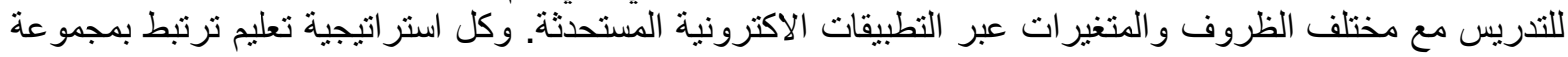

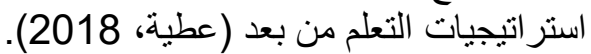
وتظهر الفروقات بين كل من الاستراتيجية والطريقة والأسلوب بشكل أوضح في الجدول رقم 1 أدناه:

\begin{tabular}{|c|c|c|c|c|}
\hline المدة الزمنية & المحتوى & الهدف & المفهوم & الفئة \\
\hline فصبلية - - شهرية- & 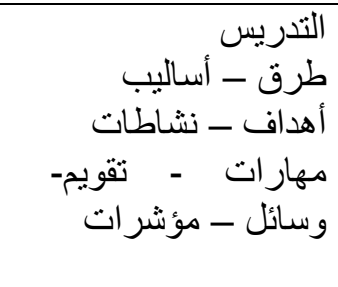 & رشاملة لعملية متكاملة & 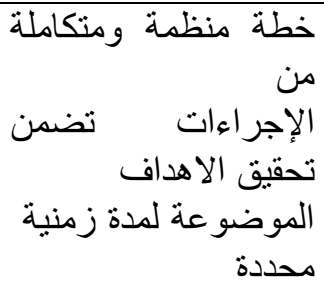 & الإستر اتيجية \\
\hline 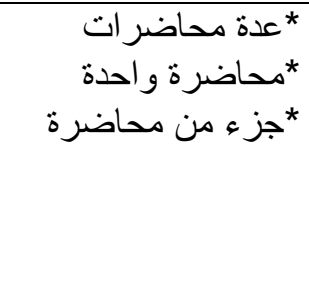 & أساليب - - محتوى نشاطات- & 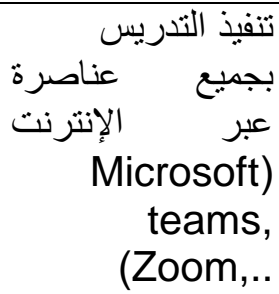 & 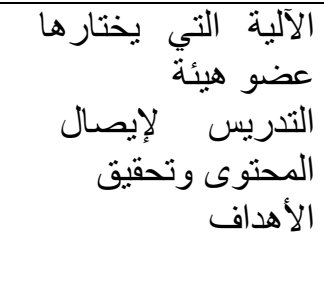 & الطريقة \\
\hline *خلال كل محاضرة محاضرة & 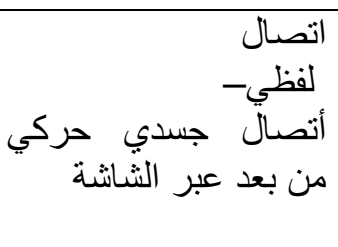 & تلتفيذ طريقة من بعد & 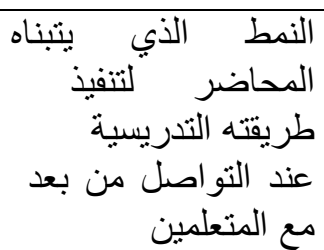 & الأسلوب \\
\hline
\end{tabular}

الجدول رقم 1

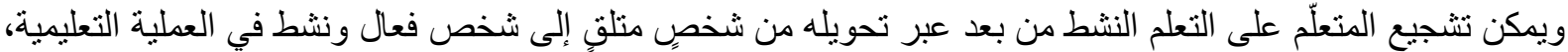

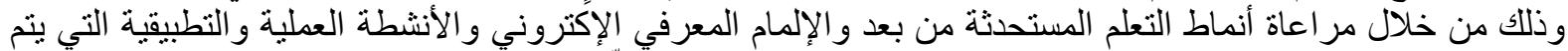

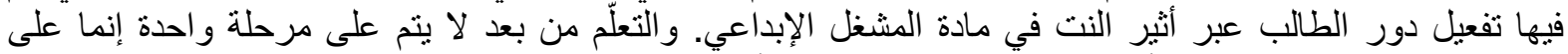
مر احل عدة كالآتي: المرحلة الأولى: الاندماج

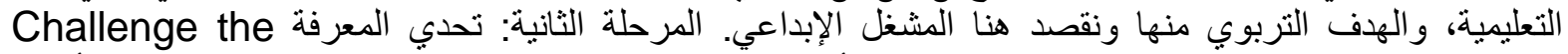

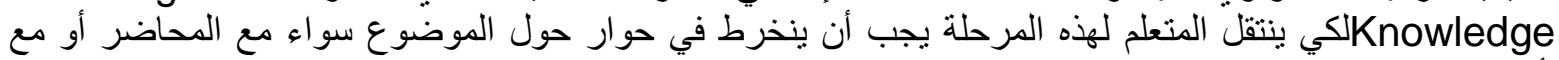

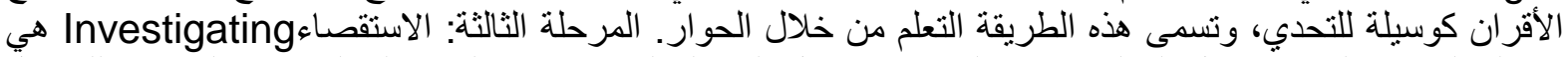

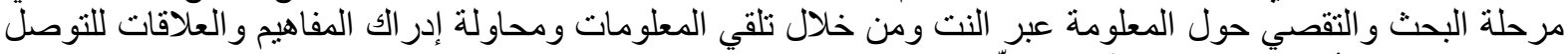

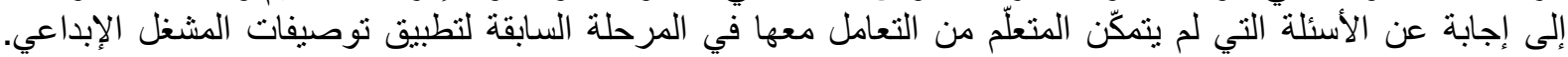


المرحلة الر ابعة اختبار الملاحظة Test the Observations: وهي محاولة تحقّق المتعلّم من صحة ودقة الإجابة

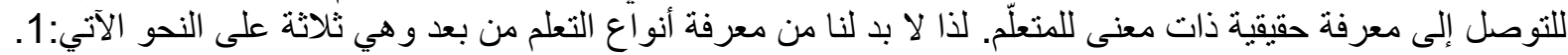
التعلم التنافسي Competitive Learning Cooperative Learning

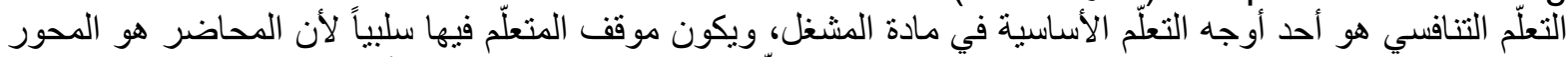

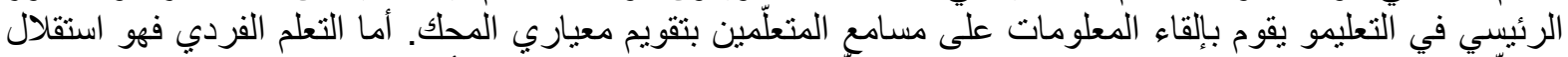

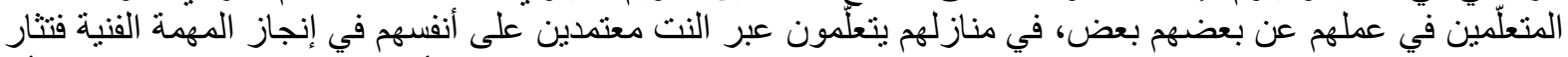

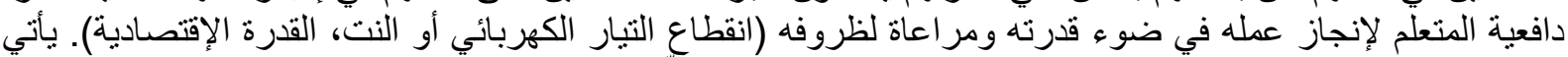

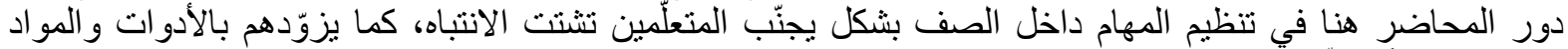

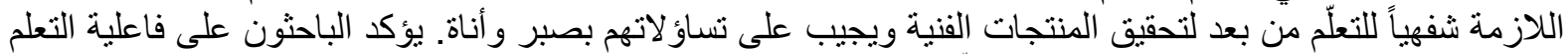

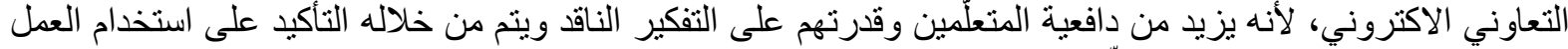

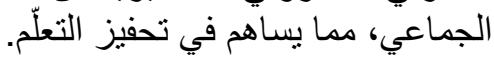

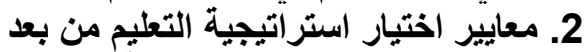

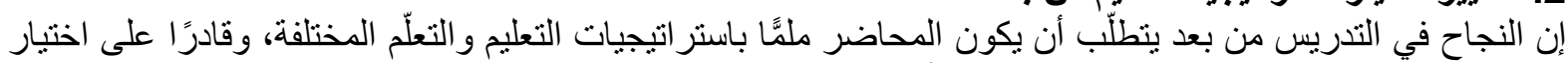

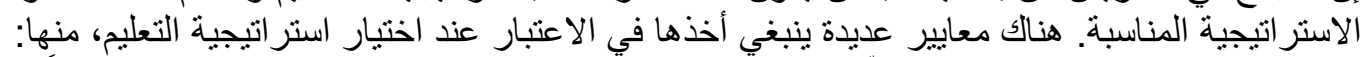

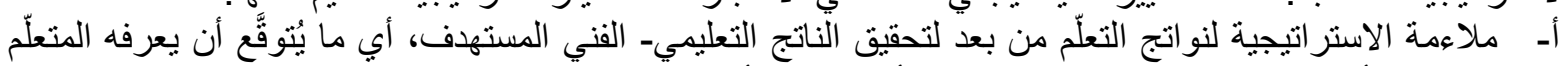

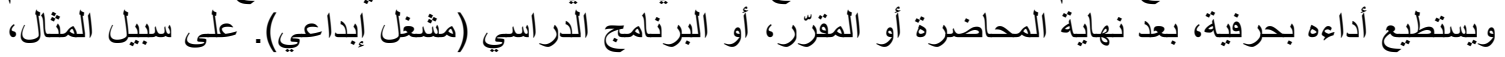

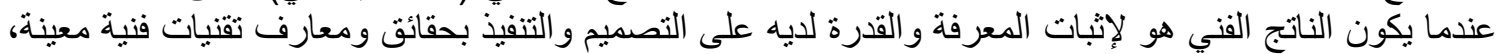
قد يستخدم المحاضر استراتيجية التعليم المرئي، أما إذا كان الناتج هو حل المشكلات، فقد يستخدم استراتيجية حل المشكلات.

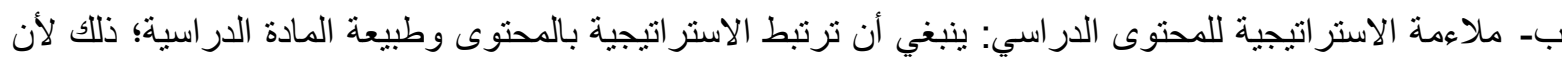

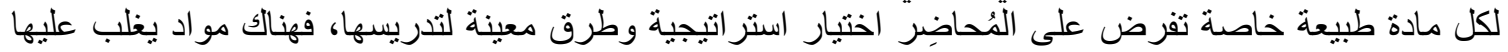

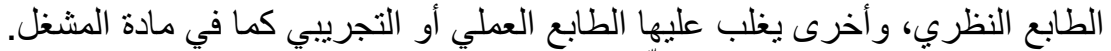

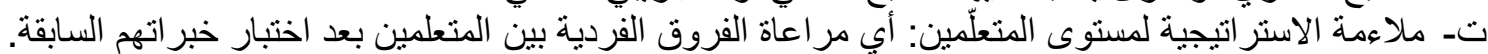

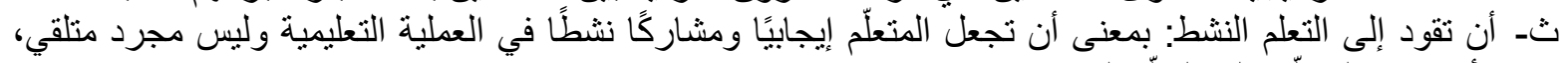

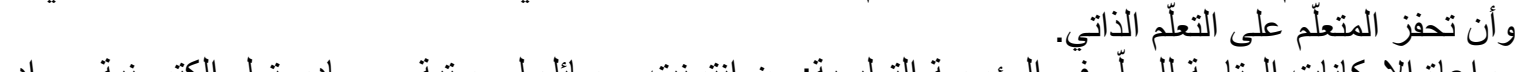
ج- مر اعاة الإمكانات المتاحة للمعلّم في المؤسئة التعليمية: من إنترنت ووسائل لوجسنية ومصادر تعلم الكترونية ومو اد

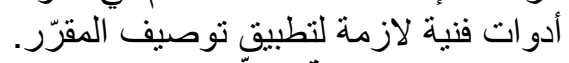

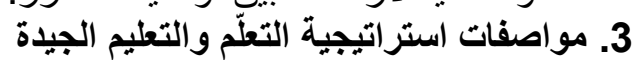

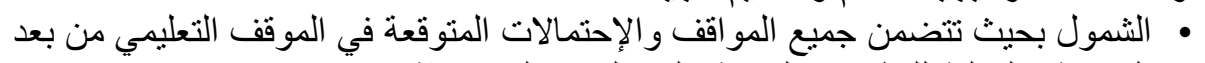

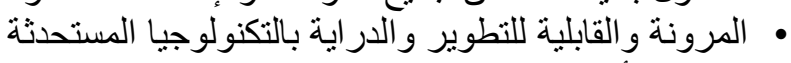

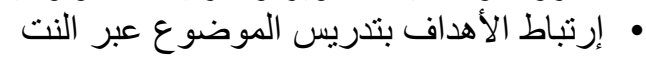

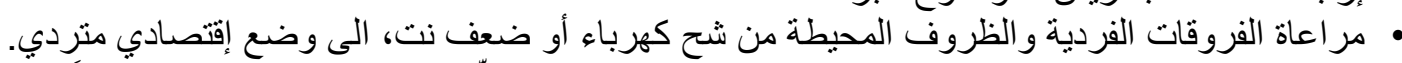

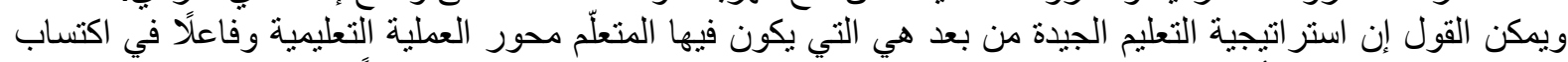

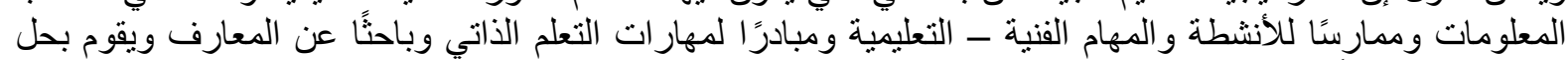

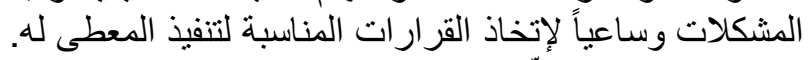

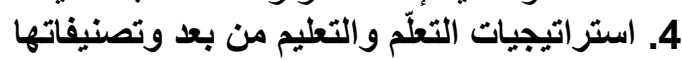

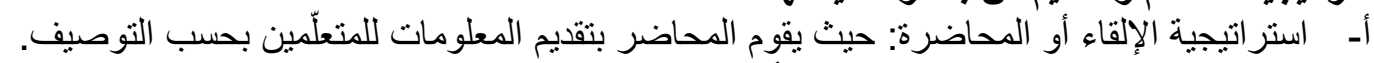

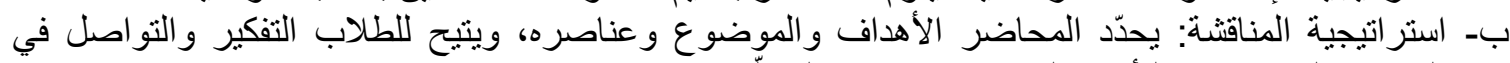

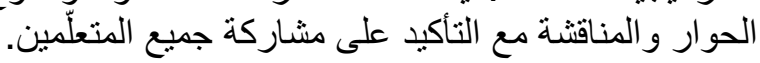

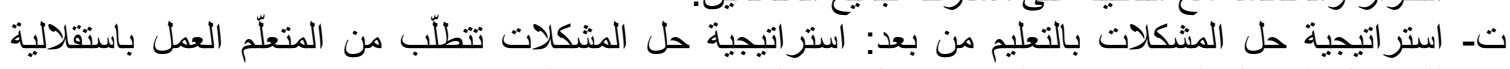

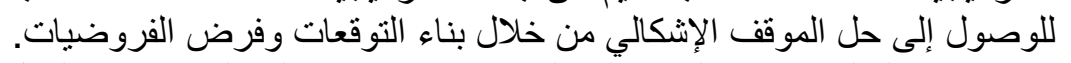

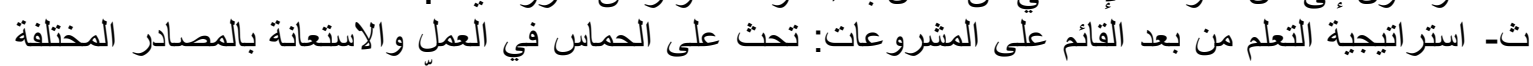

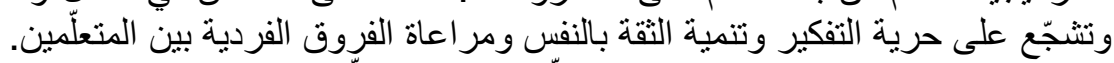

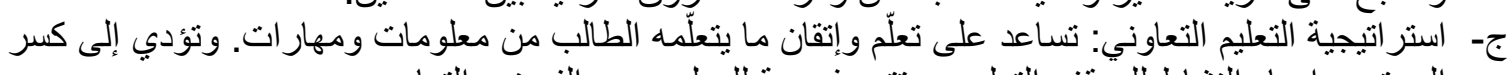

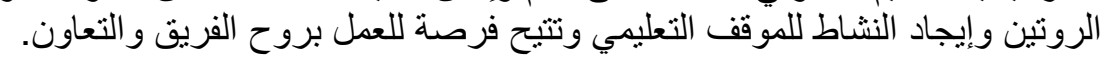


ح- استر اتيجية العصف الذهني: تسعى لتوليد أفكار جديدة، وتسهم في تنمية قدرات المتعلّمين على الإبداع و التفكير

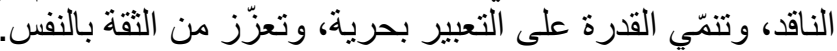

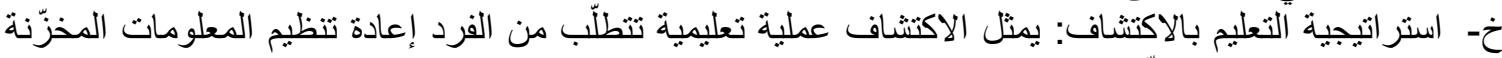

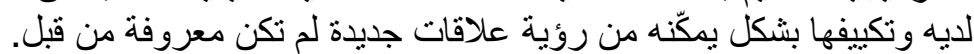

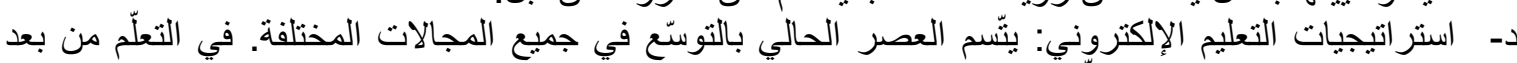

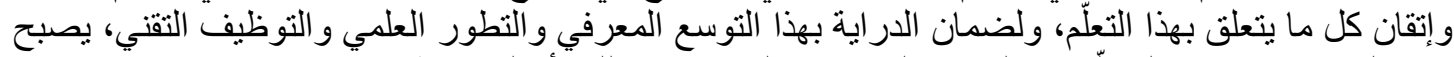

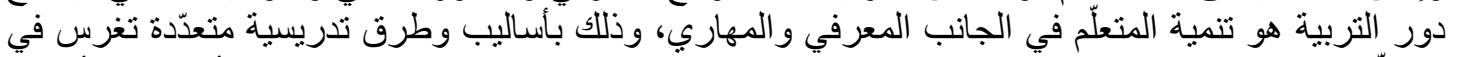

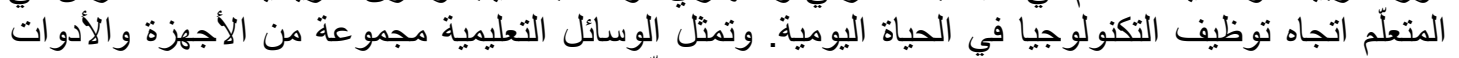

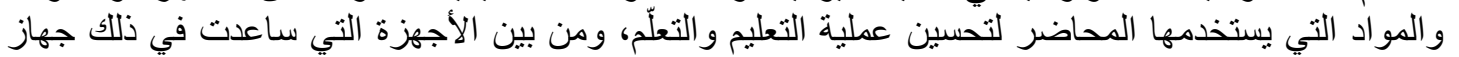

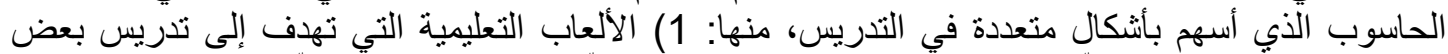

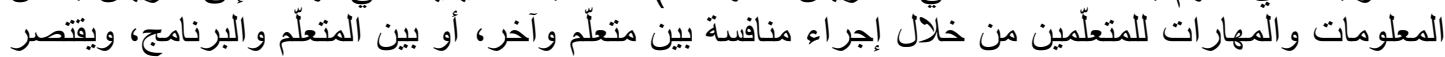

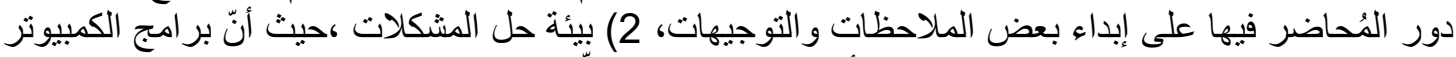

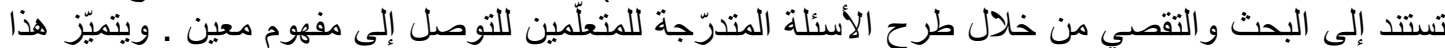

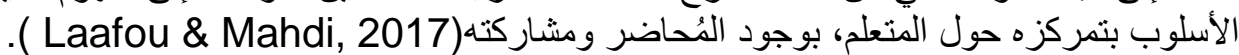

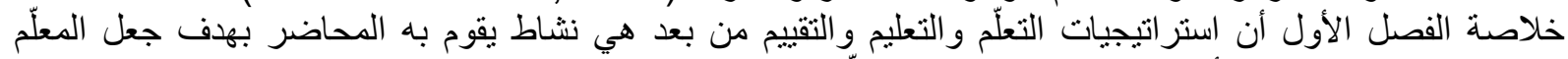

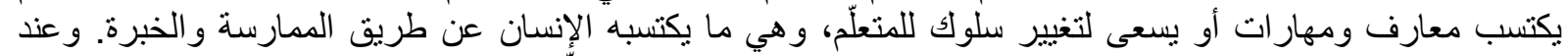

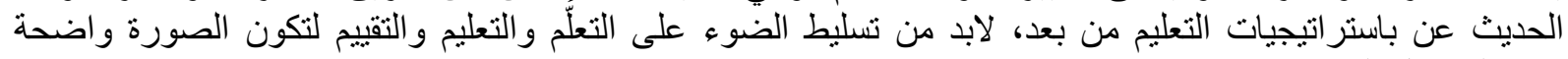

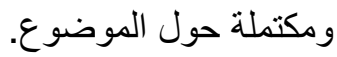

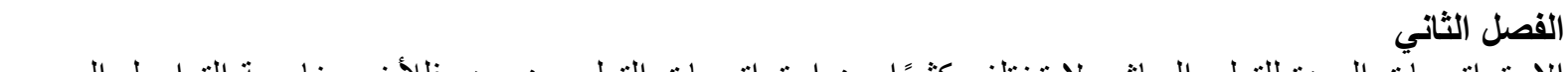

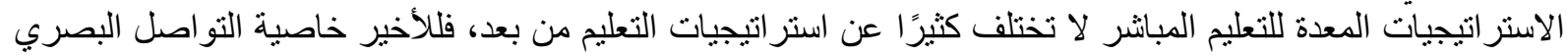

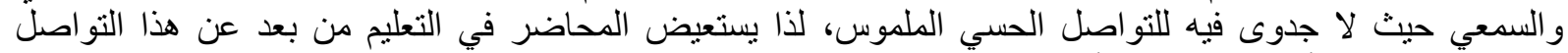

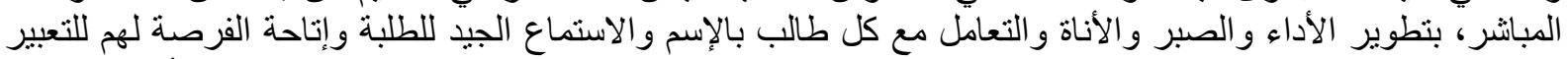

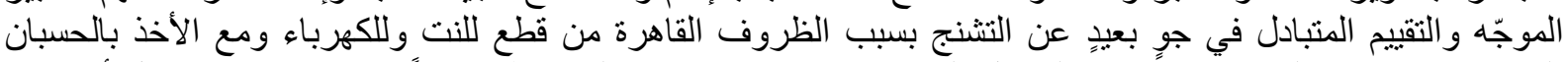

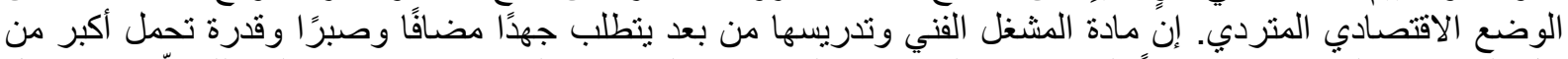

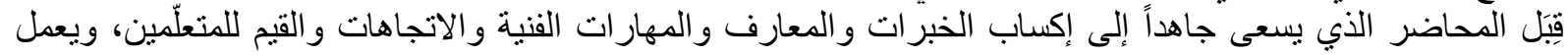

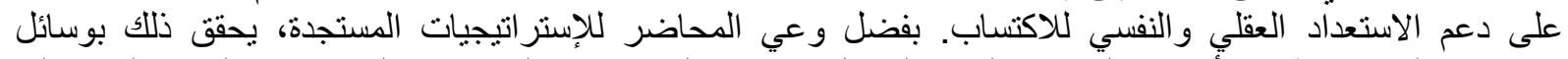

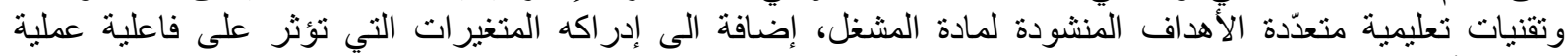

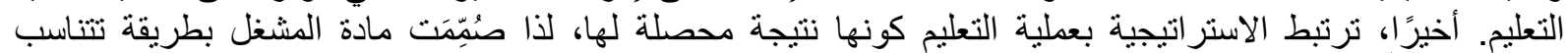

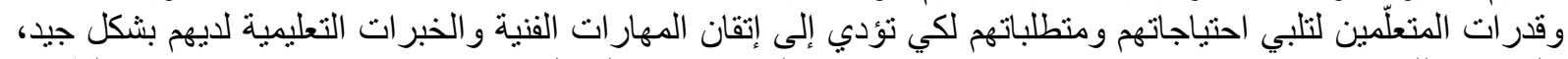

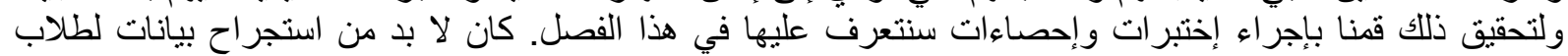

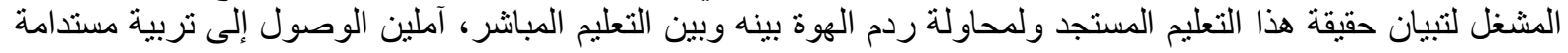

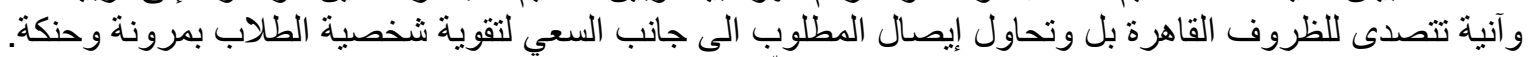

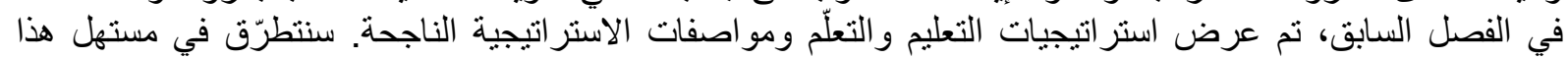

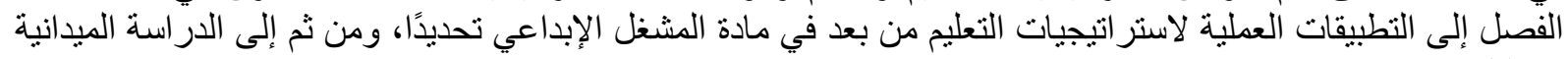

و وتحليل نتائجها.

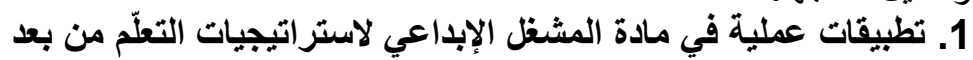

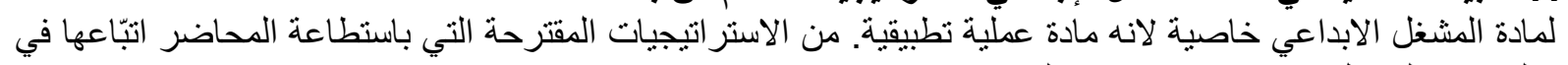

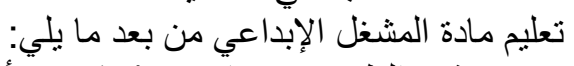

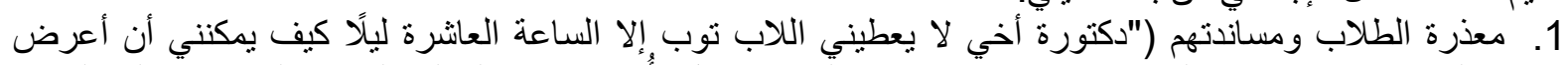

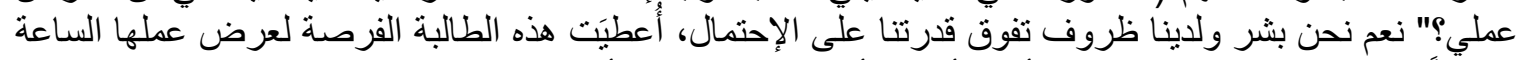

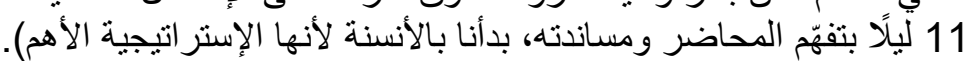

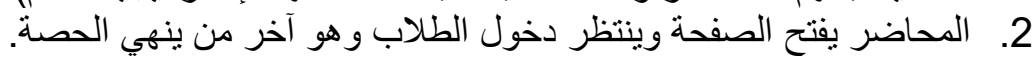

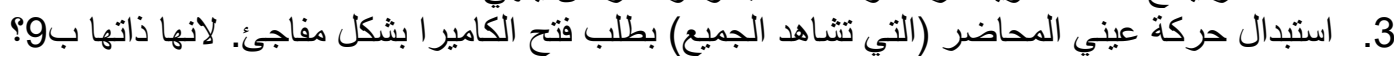

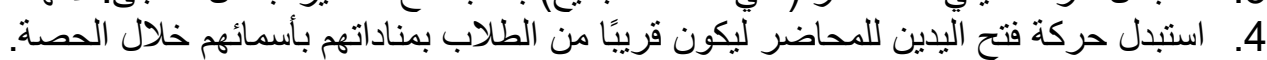

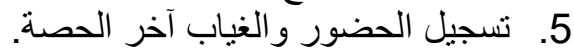
6. للبعد عن الملل في التركيز على الثانشة، يطلب المحاضر قلب الأدوار، فيسمي أحد الطلاب لبأخذ دور المحاضر لفترة قصيرة الفيرة 7. التقييم المستمر لمادة المشغل الفني خلال كل نشاط 


\section{DISTANCE LEARNING, TEACHING AND EVALUATION STRATEGIES}

IN THE SUBJECT OF "CREATIVE WORKSHOP" FOR EARLY CHILDHOOD

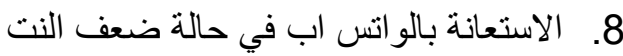

9. استبدال حركات الجسد بالتعليم من بعد برفع معنويات الطلاب عبر الطلب منهم فتح كامير اتهم بشكل مفاجئ و الطلب

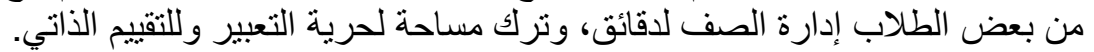

$$
\text { يمثّل الرسم البياني رقم } 2 \text { أدناه استر اتيجيات تعليم الششغل الإبداعي. }
$$

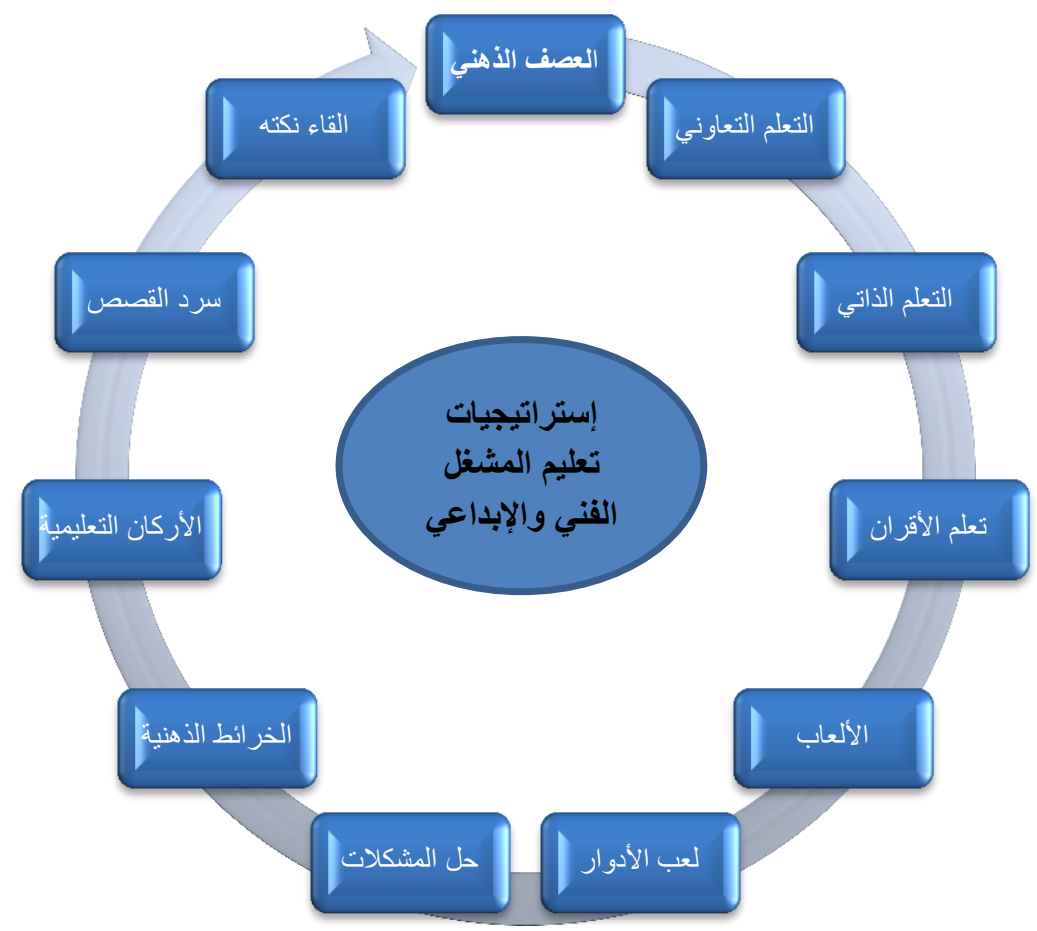

رسم بياني رقم 2

2. 2. الدراسة الميدانية

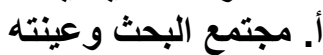

يتألف مجتمع البحث من جميع طلاب المشغل الفني الإبداعي في سنوات الإجازة الثناث في الجامعة اللبنانية كلية التربية-

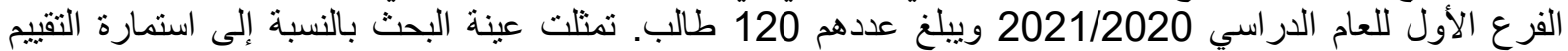

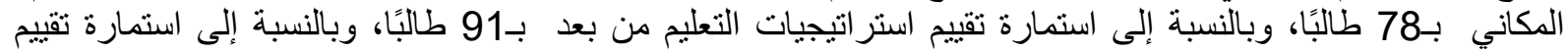

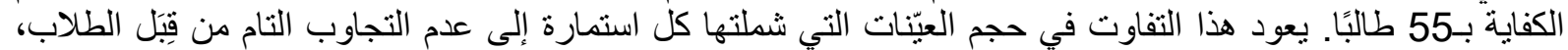

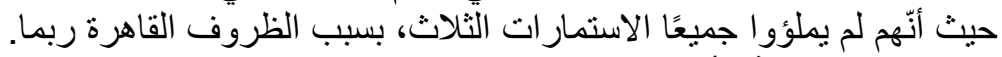

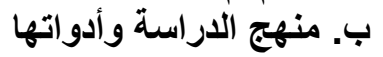

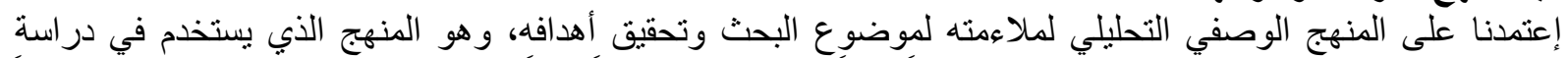

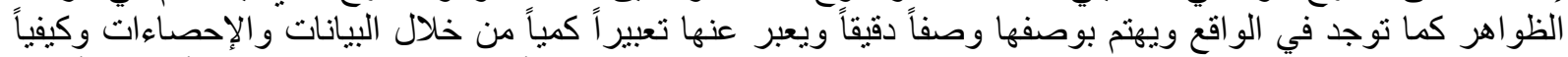

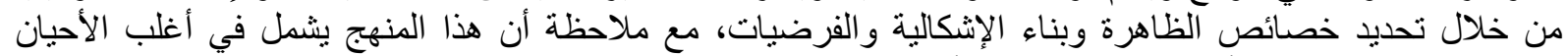

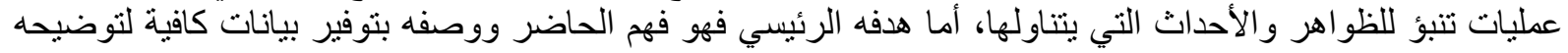

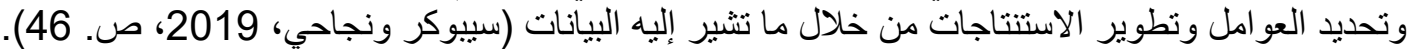

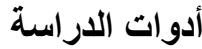
اعتمدنا في هذه الدر اسة على أداة الإستبانة، يُعرَّف الإسنبيان أو الإستمارة على أنها أداة لجمع البيانات تتألف من مجمو عة الإنة

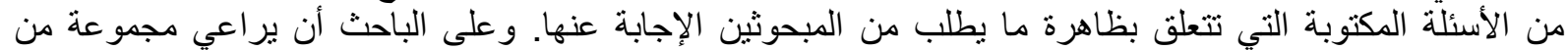

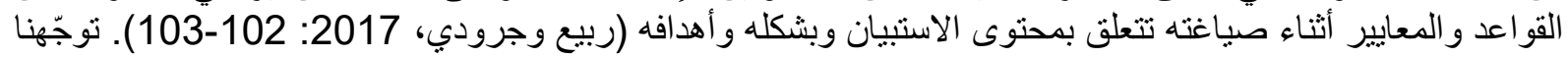




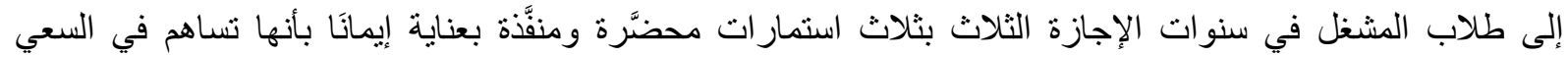

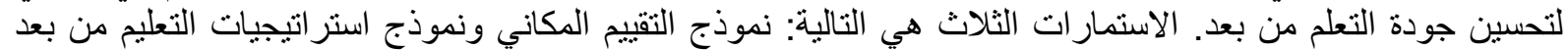
ونموذج تقييم الكفاية.

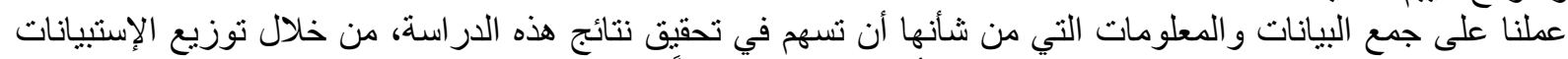

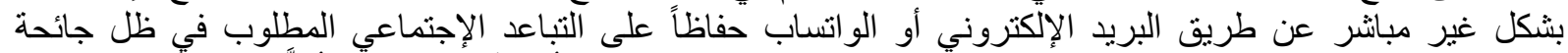

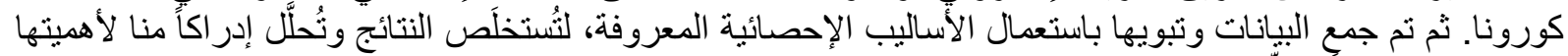

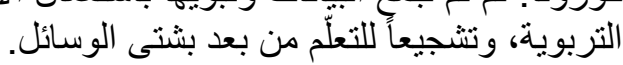
ج. تحليل نتائج الاستبيانات: تم تحضير الاستمار ات من خلانل برنامج Google forms وتم تحليل نتائجها بواسطة برنامج الـ SPSSو هو برنامج

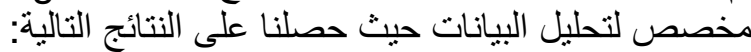

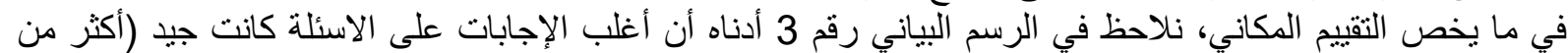

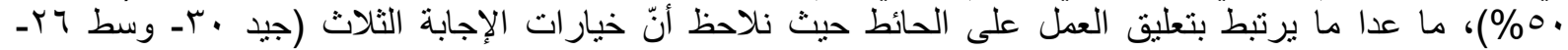

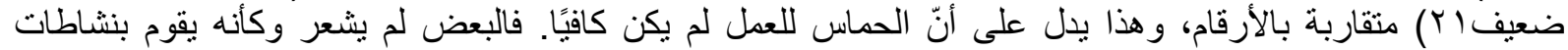

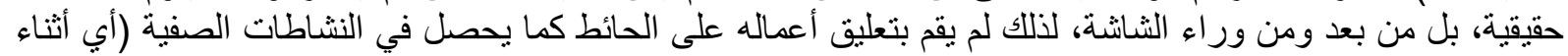

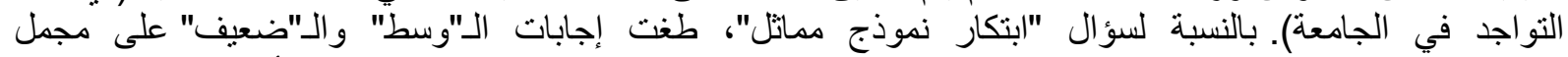

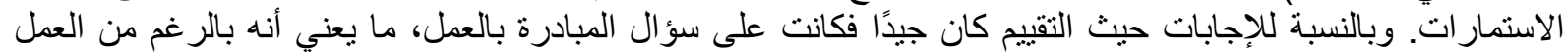

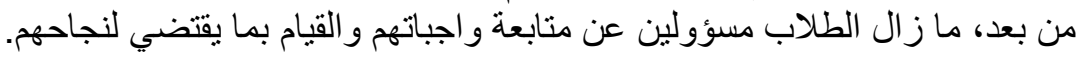

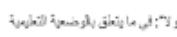

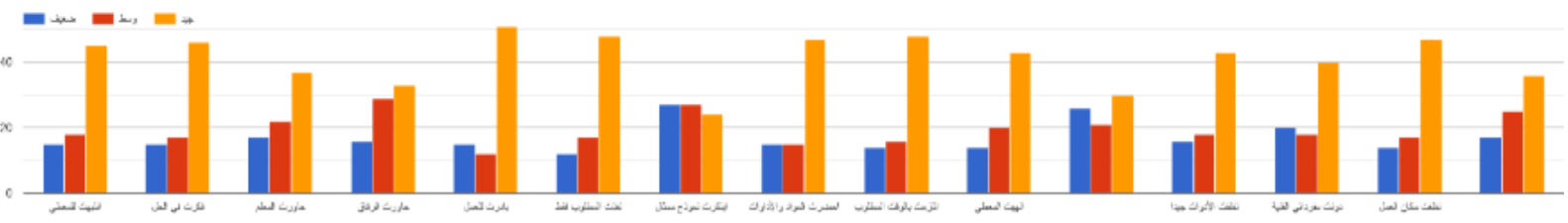

رسم بياني رقم 3

بالنسبة لتقييم الكفاية، وهو عبارة عن سؤال واحد، أجاب عليه 00 والب حسب الراب الرقم البياني رقم 4 أدناه. كانت إجابات

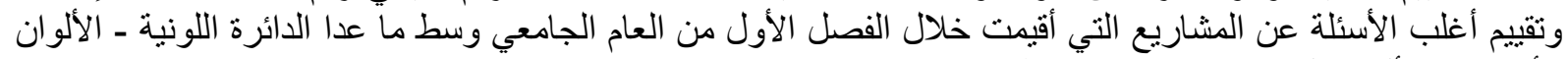
الأساسية و الألوان الأنمّة المنة فكان تقييمها جيدًا.

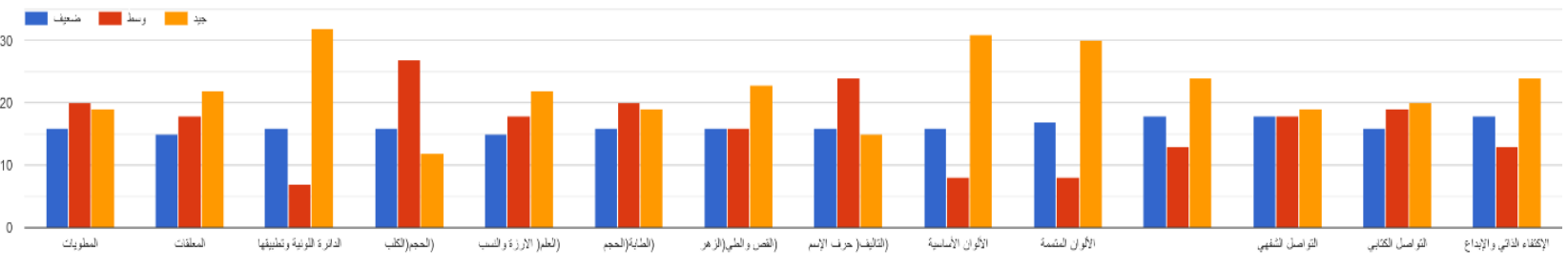

$$
\text { رسم بياني رقم } 4
$$

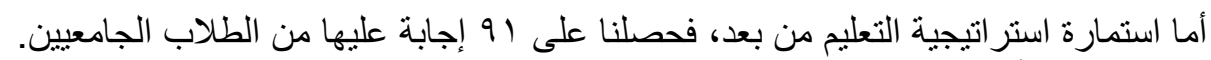

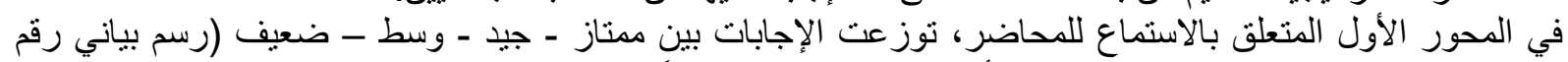

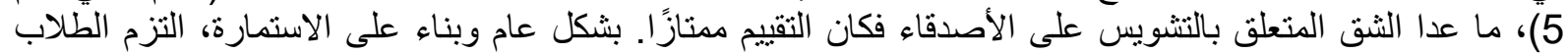

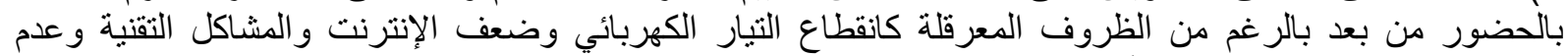

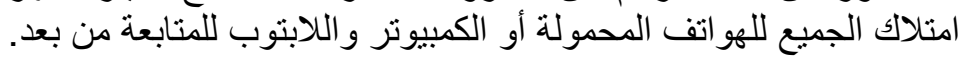




\section{DISTANCE LEARNING, TEACHING AND EVALUATION STRATEGIES}

\section{IN THE SUBJECT OF "CREATIVE WORKSHOP” FOR EARLY CHILDHOOD}

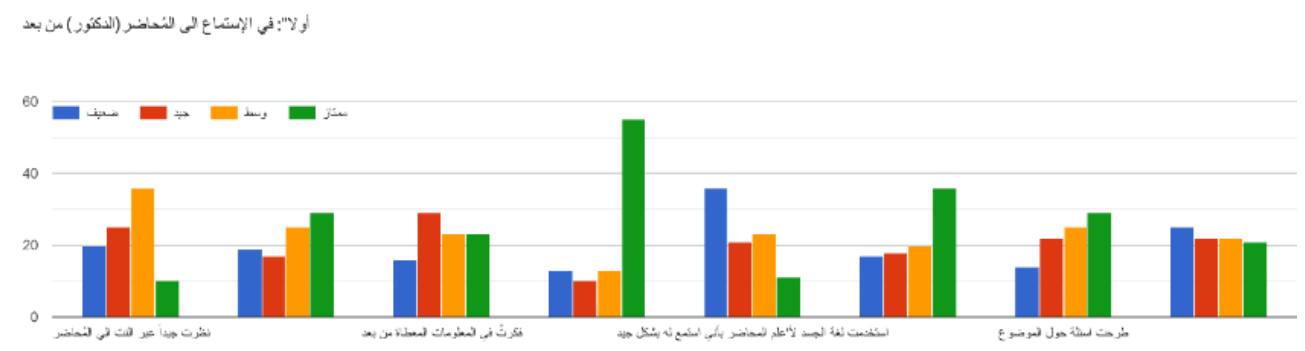

$$
5 \text { رسم بياني رقم }
$$

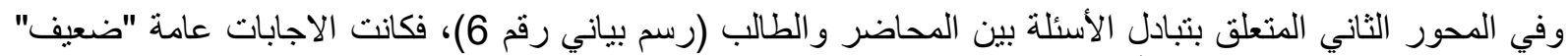

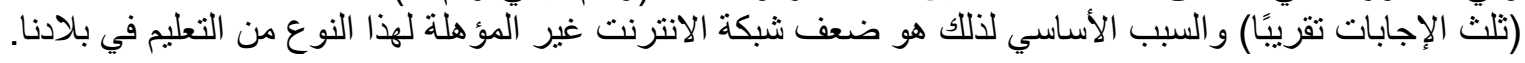

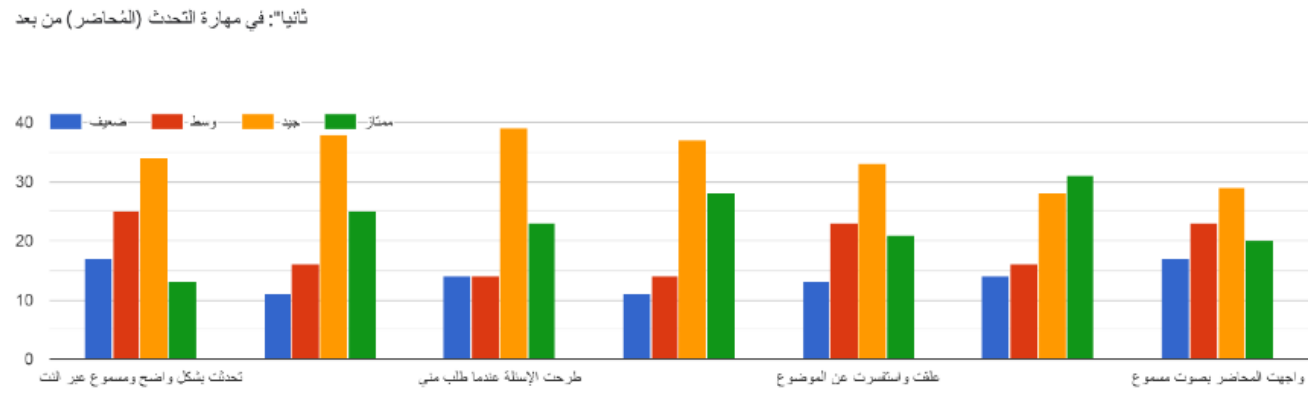

$$
\text { رسم بياني رقم } 6
$$

وفي ما يخص المحور الثالث المتعلق بمهارة التفكير من بعد (رسم بياني رقم 7)، وبشكل خاص ربط الأفكار مع بعضها،

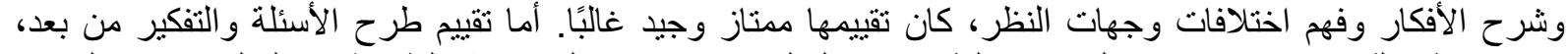

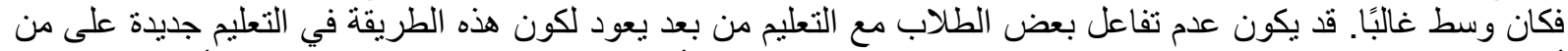

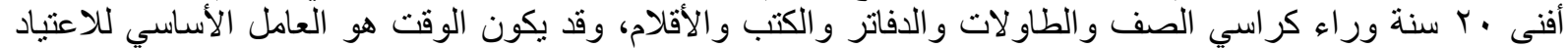
على هذه الطريقة. وأخيرًا، جاء تقييم السؤ ال المتعلق بتوسيع المدارك والتر والأفكار وسط عامة. ثالثا": في مهارة الثنفكير من بعد

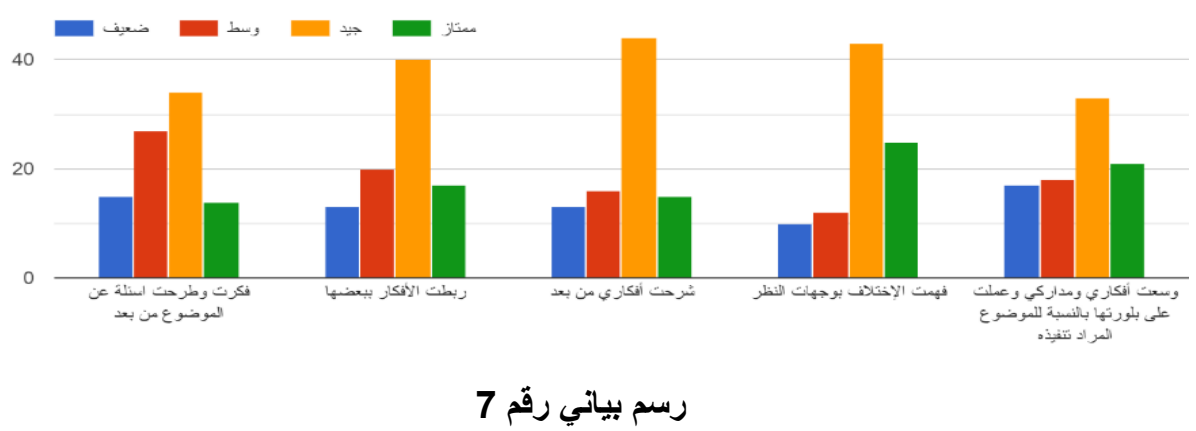

في ما يتعلق بالمحور الأخير حول اللباقة وحسن التصرف (رسم بياني رقم 8)، كان تقييمه مدتاز بالنسبة لأغلبية

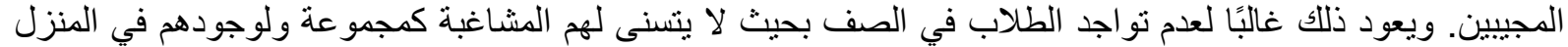
بالقرب من ذوييهح مما يظهر حس المسؤولية لديهخ والضغط لئه على أنفسهم لفهم المعلومات كونها الوسيلة الوحيدة المتاحة للتعلّم. 


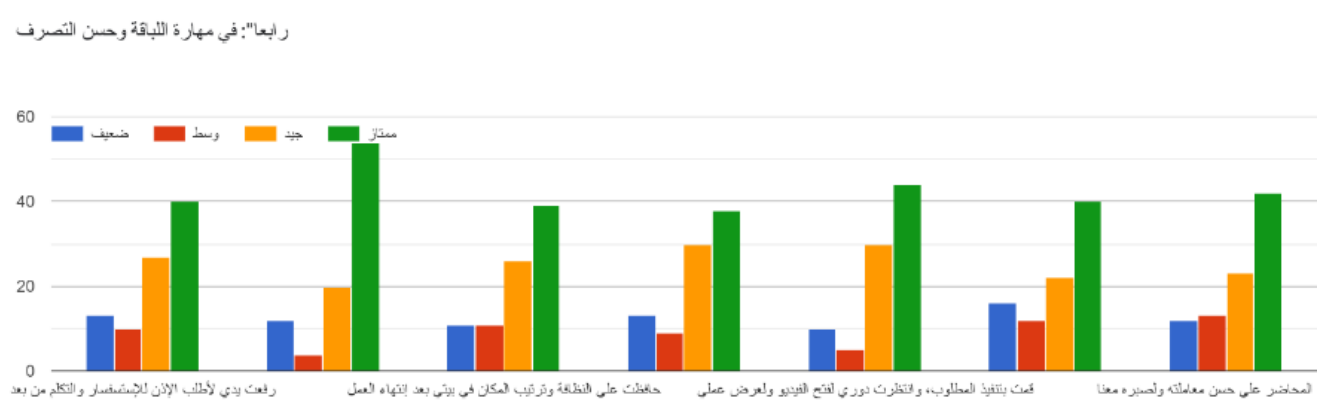

8 رسم بياني رقم 8

الخاتمة

يتغيّر العصر ويتطوّر بسر عة بسبب ثورةٍ تكنولوجيةٍ دفعت الإنسان نحو البحث والتقصي عن أفكار جديدة قادرة على وإنى

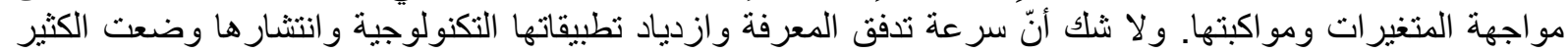

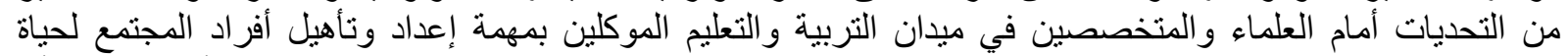

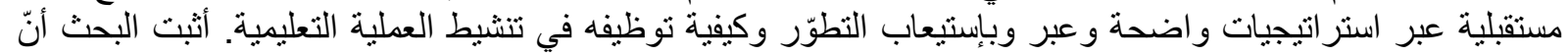

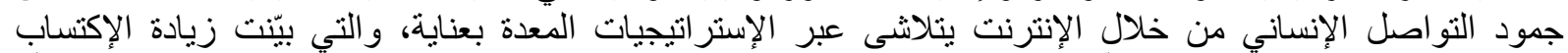

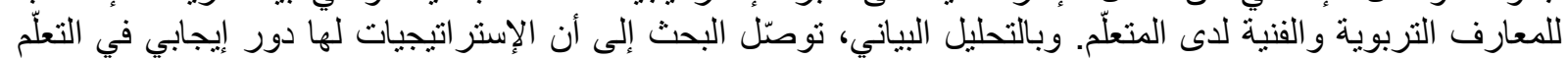

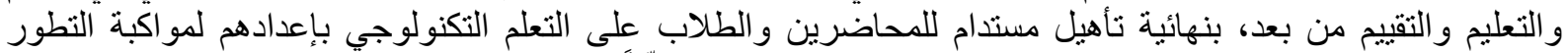

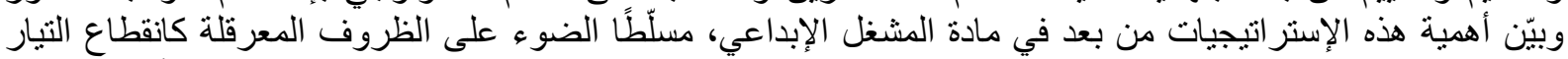

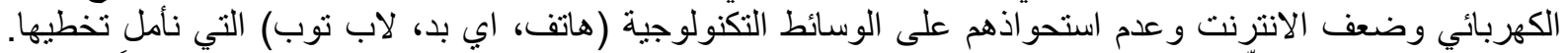

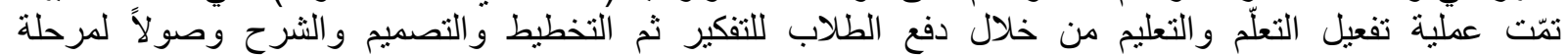

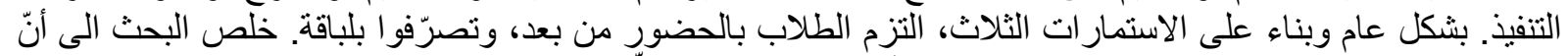

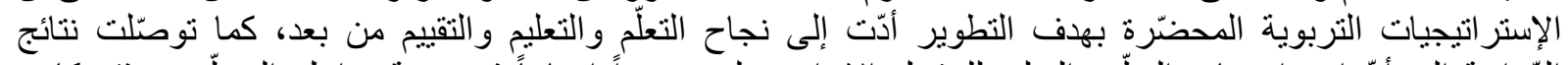

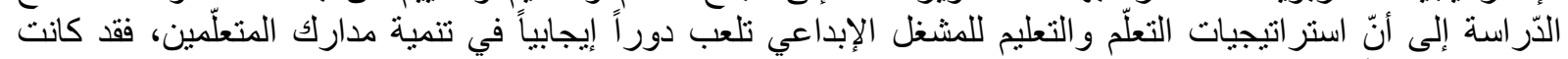

درجة استجابة أفر اد العينة جيدة.

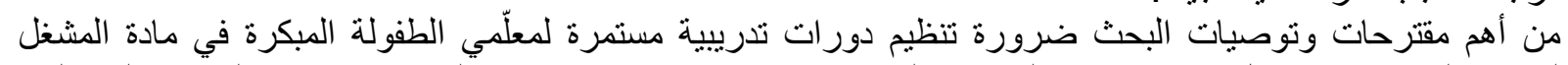
لتعميق المعرفة في مجال استر اتيجيّات التدريس الحديثة ودور ها في تنمية مهار ات التنكير الإبداعي النقدي و الناقد لدى الدى المتعلَّمين.

الملحق رقم الجمان 1

الجامعة اللبنانية

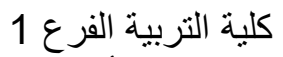

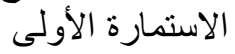

استمارة تقييم إستر اتيجية التعليم من بعد في مادة المشغل الفني

\begin{tabular}{|c|c|c|c|c|c|}
\hline 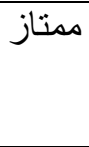 & جيد & وسط & ض ف ض & 1-الإستماع الى المُحاضر(الدكتور) من بعد & 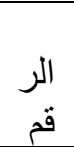 \\
\hline & & & & نظرت جيداً عبر النت الى المُحاضر & \\
\hline & & & & لم اتحدث جانبا او اقاطع الشرح من بعد & \\
\hline & & & & فكرتُ في المعلومات المعطاة من بعد & \\
\hline & & & & لم اشوش واتحت المجال لآخرين للتحدث & \\
\hline & & & & بشكل جيد لغنة الجسد لأُعلم المحاضر بأني استمع له & \\
\hline & & & & توابلغت المحاضر بذلك وتثويش الصوت أثناء المحاضرة & \\
\hline & & & & طرحت اسئلة حول الموضوع & \\
\hline & & & & لخصت و اعدت صياغة ما فهمه الآخرون من الشرح & \\
\hline
\end{tabular}




\section{DISTANCE LEARNING, TEACHING AND EVALUATION STRATEGIES}

IN THE SUBJECT OF "CREATIVE WORKSHOP" FOR EARLY CHILDHOOD

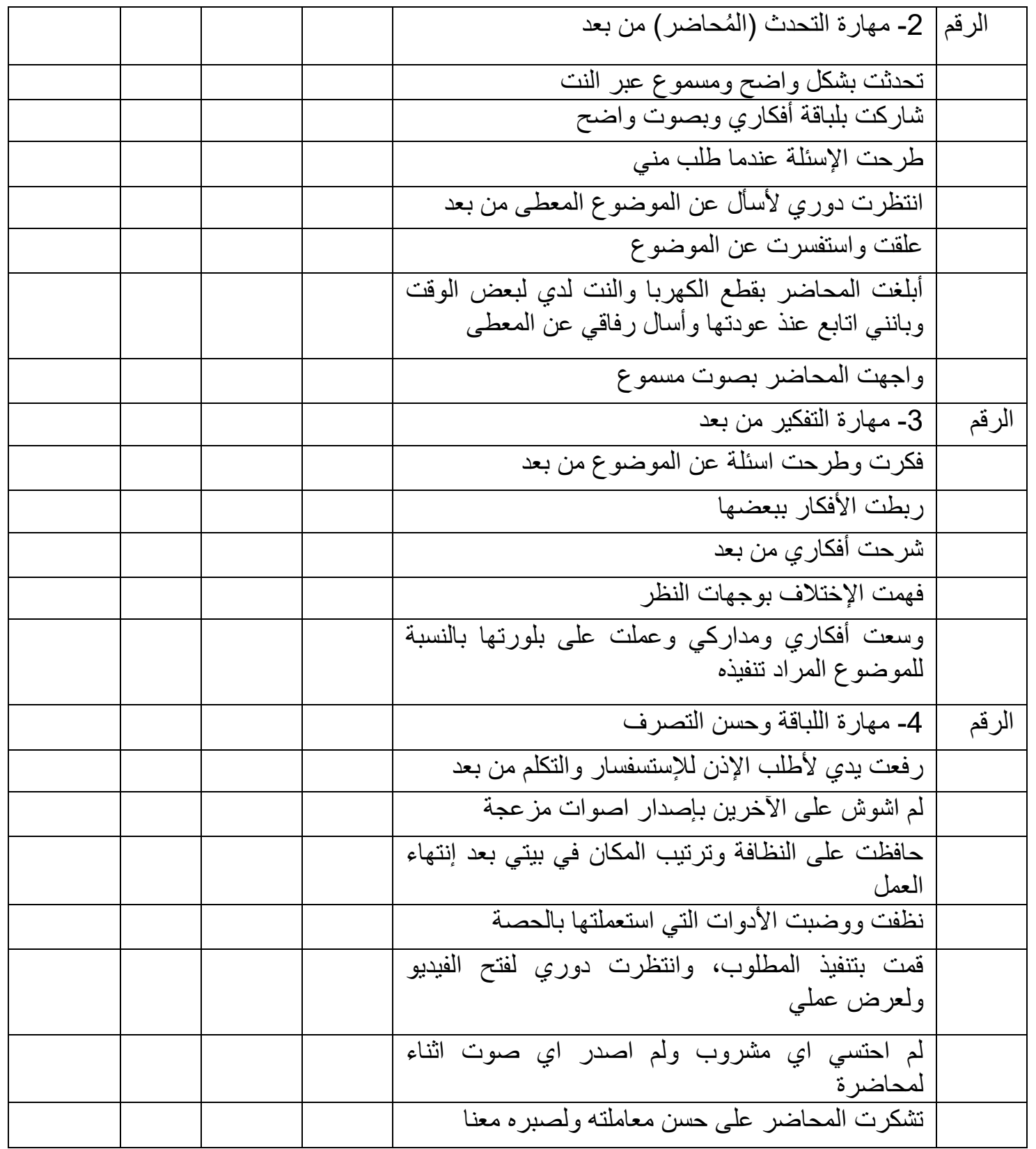




\begin{tabular}{|c|c|c|c|c|c|c|}
\hline الملاحظات من قبل المعلم & المجموع & جيد & وسط & ض ضعي & الوضعية التعليمية & العدد \\
\hline & & & & & انتبهـثُ للمعطى & .1 \\
\hline & & & & & فكرتُ في الحل & .2 \\
\hline & & & & & حاورتُ المعلم & .3 \\
\hline & & & & & حاورتُ الرفاق & .4 \\
\hline & & & & & بادرتُ للعمل & .5 \\
\hline & & & & & نفذتُ المطلوب فقط & .6 \\
\hline & & & & & ابتكرثُ نموذج ممثال & .7 \\
\hline & & & & & و حضراتُ & .8 \\
\hline & & & & & المطلوب & .9 \\
\hline & & & & & أنِيتُ المعطى & 10 \\
\hline & & & & & الُقلتُ & 11 \\
\hline & & & & & نظفتُ الأدو ات جيدًا & 12 \\
\hline & & & & & دوّنتُُ مفرداتي الفنية & 13 \\
\hline & & & & & نظفتُ مكان الَعمل & 14 \\
\hline & & & & & فيّمتُُ وقاربتُُ عملي & 15 \\
\hline
\end{tabular}

الاستمارة الثالثة

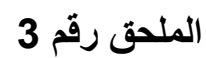

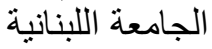

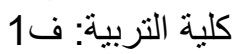
تقييم الكفاية

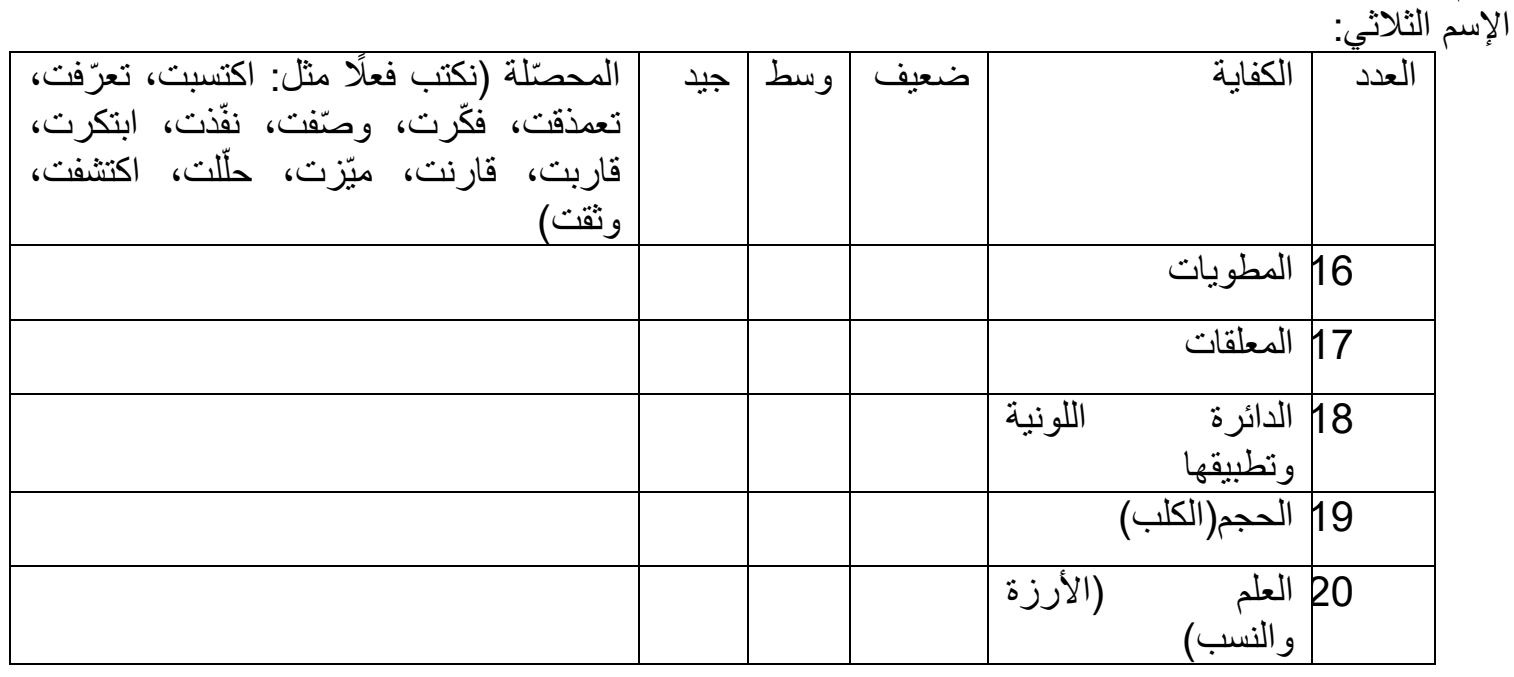




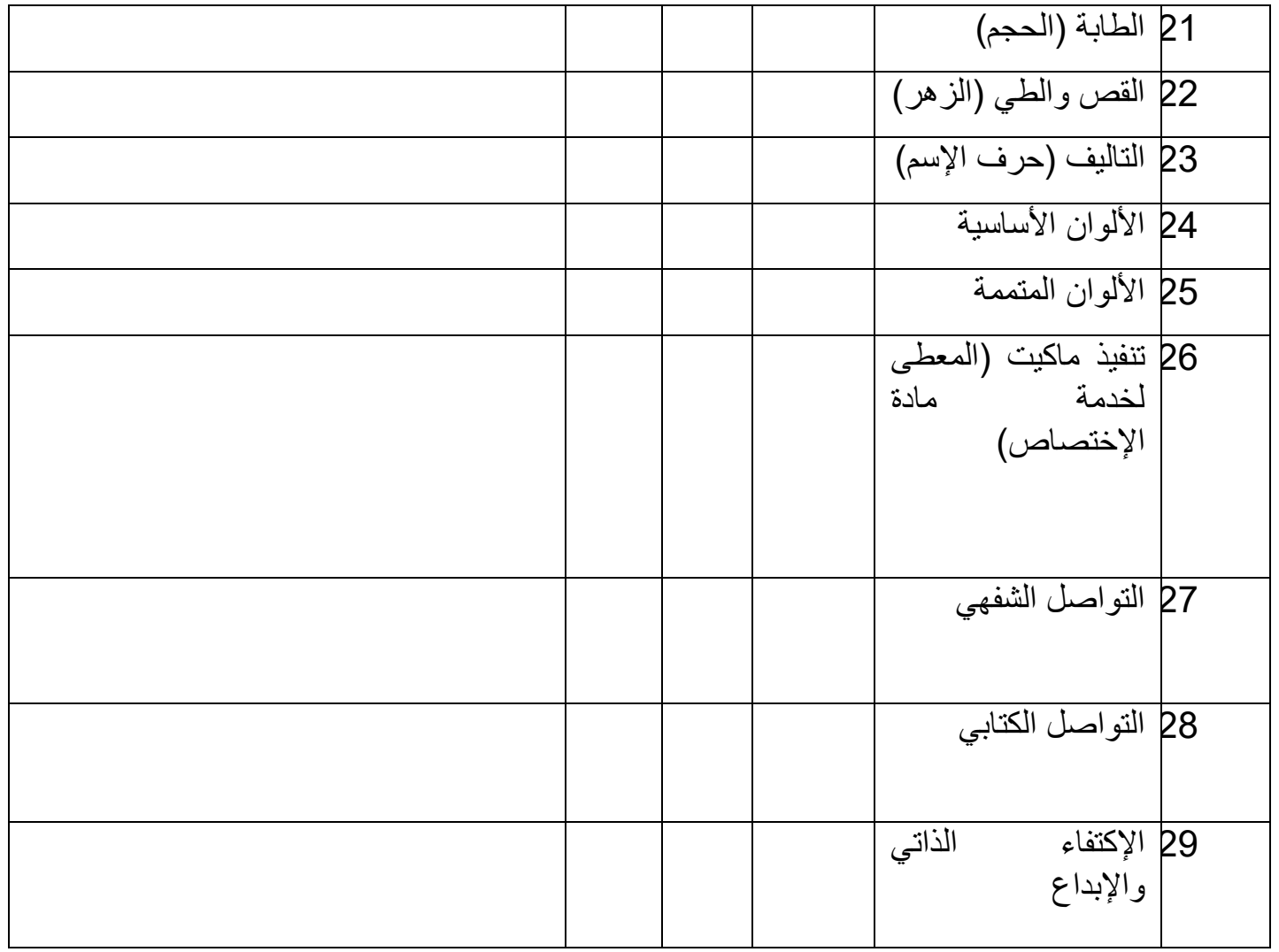

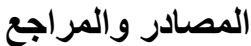

باير، ر. (2008). تاريخ علم الجمال من خلال الفلسفة والنقد والفن (د. ميثال عاصي، مترجم). بيروت: دار نلسن. .45 ص جابر، ع. ج. (1999). استر اتيجيات التدريس و التعلم. القاهرة: دار الفكر العربي.

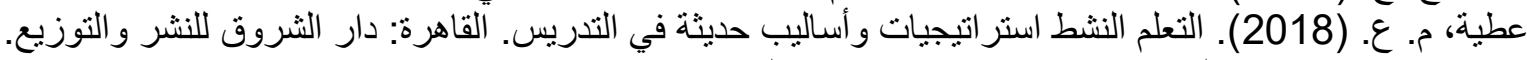

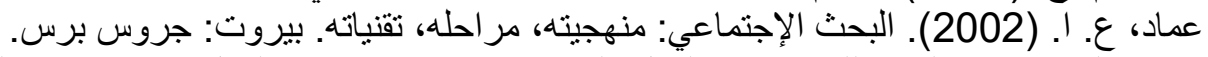

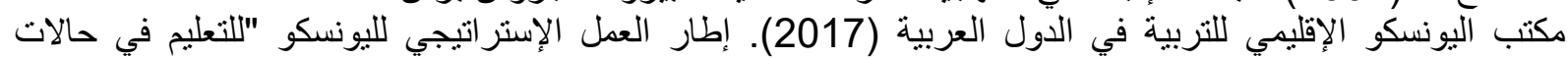

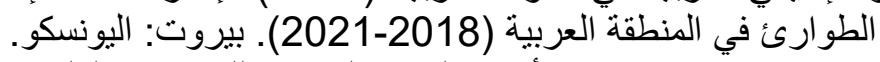

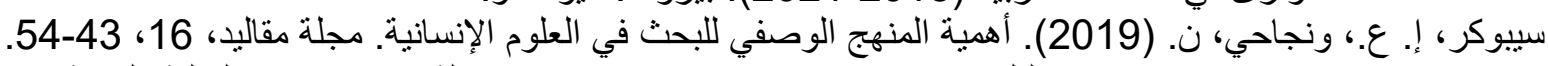
ربيع، م. وجرودي، ر. (2017). تحليل الاسنبيان باستخدام برنامج Spss. مجلة الاقتصاديات المالية البنكية وإدارة الأعمال (3)،

Allen, I. E. \& Seaman, J. (2013). Changing course: Ten years of tracking online education in the United States. Needham, MA: The Sloan Consortium.

Burns, M. (2020). Enseignement en ligne en situation d'urgence : 7 étapes pour bien commencer. Blog Education pour tous, Global Partnership. https://www.globalpartnership.org/fr/blog/enseignement-en-ligne-ensituation-durgence-7-etapes-pour-bien-commencer

Laafou, M., \& Mahdi, K., (2017). La technologie mobile au service de l'enseignement et l'apprentissage : le cas de l'ENS Tétouan. EpiNet. http://www.epi.asso.fr

Lagoutte, D. (2002). Enseigner les arts visuels. Paris : Editions Hachette Education. 